\title{
Comparison of Linear Quadratic - Regulator and Gaussian - Controllers' Performance, LQR and LQG: Ball-on-Sphere System as a Case Study
}

\section{Usman Mohammed}

Department of Elect/Elect Engineering, Nile University of Nigeria, Abuja, Nigeria

Email: usman070064@nileuniversity.edu.ng

\section{Tologon Karataev}

Department of Elect/Elect Engineering, Nile University of Nigeria, Abuja, Nigeria Email: tologon.karataev@ nileuniversity.edu.ng

\section{Omotayo O. Oshiga}

Department of Elect/Elect Engineering, Nile University of Nigeria, Abuja, Nigeria Email: ooshiga@nileuniversity.edu.ng

\section{Suleiman U. Hussein}

Department of Elect/Elect Engineering, Nile University of Nigeria, Abuja, Nigeria Email:elsuligh@gmail.com

\author{
Sadiq Thomas \\ Department of Computer Engineering, Nile University of Nigeria, Abuja, Nigeria \\ Email: sadiqthomas@nileuniversity.edu.ng
}

Received: 12 February 2021; Accepted: 15 March 2021; Published: 08 June 2021

\begin{abstract}
With the state-space method, many controllers can be designed optimally. LQR and LQG are two of these controllers. These two controllers are covered much in the literature. Despite this, not many works cover the ball-onsphere system. Therefore, the research designed optimal LQR and LQG controllers for the system of ball-on-sphere and did a comparative analysis between the two. System dynamics were first investigated and the mathematical model was derived. After that, the system was linearized and then the state-space representation was obtained. Using this representation, the two controllers were designed and applied to the system for control. The control was done based on the specified desired system performance. Finally, the controllers' performances were analyzed and compared. Results obtained showed that both controllers met the desired system performance. With $\theta_{x}$ is $87.14 \%$ and $\theta_{y}$ is $86.43 \%$ less than their respective unregulated settling times, LQR satisfied the at least $80 \%$ performance requirement more than LQG. For LQG, $\theta_{x}$ is $82.35 \%$ and $\theta_{y}$ is $82.95 \%$ less than their respective unregulated settling times. These values are less than that of LQR. It was also observed that minimizing the total control energy leads to maximizing the total transient energy but LQG maximizes the total transient energy more than LQR. Another finding was that all states played role in regulating the controller to the desired system performance. Without regulation, LQG was found to be more efficient than LQR but in general, LQR is more efficient than LQG because, in LQG, settling time (of ball's angles) of less than $1.00 \mathrm{sec}$ could not be realized. LQR is $4.79 \%$ and $3.48 \%$ more efficient than LQG in $x$ and $y$ directions, respectively, for the ball's angles settling time. This research is significant because it is the first to design and do a comparative analysis of LQR and LQG controllers for the ball-on-sphere system. Therefore, bridging the existing gap in the literature is the value of this research.
\end{abstract}

Index Terms: Comparison; LQG; Ball-on-sphere; LQR; System

\section{Introduction}

Control media, control subject, and controlled object are components that made up a control system. Control system's knowledge can be applied in many ways. For example, variables in devices, machines, mechanisms, etc., can 
be changed or maintain by applying this knowledge. This means that, with the application of different control schemes, the devices that are being controlled could be made to attain a specified preordained ideal state [1]. Control system plays a critical function as one of the essential bedrocks of contemporary social development. Therefore, there exists a direct correlation between humans' daily lives and control systems, which means that many applications in humans' daily life cannot be separated from control systems. These applications include; automated aircraft landings, temperature adjustment for conditioning air, changing the lifting speed of an elevator, etc. Conversely, control systems are not restricted to only humans' daily lives. They are commonly used in industry and, of course, scientific research [2]. The analysis of stability and dynamics of a system that is made up of an object and a ball on it has been often attempted in recent times for control purposes. These kinds of systems are widely used in the control engineering field, as well as in education, for research and industrial purposes. They include ball-on-sphere [3], ball and beam [4], ball-on-wheel [5], etc.

A laboratory experiment, that is web-based and can be accessed, in real-time, remotely, for controlling the system of ball-on-sphere is suggested in [6]. The system comprises a ball, 2 friction wheels, a sphere, and 2 motors. The motors drive the friction wheels while the friction wheels control the sphere's rolling along the 2 horizontal axes.

So, balancing the ball on the sphere is the main objective of the control experiment and this balancing is achieved by controlling the sphere's rolling. Due to its under-actuated, nonlinear, as well as, unstable nature, it is not an easy task to control this kind of system. Understanding the fundamental principles of control theory and nonlinear dynamics is very important. So, from an educational perspective, this system is appropriate for illustrations in class and experiments in a control laboratory to plainly illustrate and underline these principles. There are systems whereby nonlinearity affects the controller or the plant. These systems are called nonlinear control systems [7]. The majority of physical systems are naturally nonlinear. Since it is difficult to analyze nonlinear systems, linearizing them about their equilibrium points to get a linear system, and use the linear model for analysis is the usual practice in engineering. The system of ball-on-sphere is nonlinear, so it can be linearized about its equilibrium point as per the conventional practice for simplicity of analysis and control. An equilibrium point is a point where all variables, input, and state, are zero [5]. For control design purposes, the exact dynamic is extremely difficult to analyze [8]. So, the system of ball-on-sphere is reduced to 2 separated systems of ball-and-wheel, by ignoring the coupling terms that are of a higher order, whereby the control of the wheel's angle balances the ball over the wheel's periphery [5].

The control engineering field has a lot of fascinating and difficult facets. One of the most difficult facets of this field is balancing. There are many control systems that balancing is used as a control scheme such as the double inverted pendulum, system of ball-on-sphere, inverted pendulum, system of ball and beam, etc. [9]. Linear Quadratic Regulator (LQR) and Linear Quadratic Gaussian (LQG) controllers are two of the most popular control schemes to balance these systems.

Feedback gain is provided by LQR which is an optimal controller. The cost function can be minimized by this controller and it has been suggested for the stabilization of frequency. There might be drifting of LQR performance because of system noise existence. The LQG and LQR controllers are comparable.

With uncertainty and noise, stable performance can be provided by the LQG controller [10].

The LQR method can serve as a formidable approach to controller designing especially for complicated systems that have a strict requirement in terms of performance. The method looks for a controller that is optimal by cost function minimization [11]. The matrices $\mathbf{R}$, input weighting matrix, and $\mathbf{Q}$, state vector weighting matrix, are the parameters of the cost function. Control input is been punished by the $\mathbf{R}$ matrix, which is positive as well as a definite matrix, while states of the system are been punished by the $\mathbf{Q}$ matrix, which is a nonnegative as well as definite matrix [12]. The state-space representation of the system is used by the LQR method and, by solving the algebraic Riccati equations, an optimal control input is obtained by the method [13]. In the optimization process of an LQR, the two critical elements are the $\mathbf{Q}$ and $\mathbf{R}$ matrices. System performances are significantly affected by how these matrices' elements are made up. Even though the selection of these matrices is entirely based on the designer's performance requirement, comprehending the problem at hand, as well as experience, plays an important role [13].

Because noise, assumed to be Gaussian, is principally taking into consideration in the output equations as well as the state equations, the LQG method is considered to be a robust control method. Moreover, in the design of the controller, the noise quantitative information is used. The LQG method is based on the principle called the separation principle. According to this principle, the optimal control, which is LQR, and the optimal estimation, which is the Kalman filter, are solved independently.

This means that the Kalman filter is designed first, which gives estimated states, then these estimated states are used to design the LQR controller as if they are exactly measurable [14]. The LQG control also uses the state-space representation of systems for controller design. In the absence of the state-space representation, LQG control needs to do identification of the system based on the provided input/output data. But when there available the state-space representation of a system, system states are first estimated using the Kalman filter and then using these estimated states LQR controller is designed [15].

For a better understanding of the two controllers' performance for the ball-on-sphere system, the two controllers are compared. 
Optimal control has been around for a long time. Two of the methods of optimal design, that are presently at hand, which are continuously getting recognition are the LQR and LQG. Designing, through performance criteria minimization that is bounded quadratic integral, of a control law is the main concept behind the LQR method [16]. The optimality concept is closely related to the control design of multiple inputs multiple outputs (MIMO) systems. Optimum controllers, otherwise best possible, are called optimal controllers. Optimal controllers usually give rise to controllers that stabilize MIMO plants based on some performance criteria. This way, a design process that is automated is provided by optimal control solutions. So, the designer will only have to decide the performance criteria. One of the popular design schemes that feedback gains are provided is LQR [17]. For research and control education purposes, a lot of experimental setups have been developed, such as inverted wedge and pendulum, ball and beam, etc., in recent past decades. These setups have underactuated, nonlinear, and unstable nature.

Because of this, they are considered to be research testing grounds in nonlinear control systems [18]. One of these control laboratory experimental setups is the ball-on-sphere system.

Even though LQR and LQG are controllers that are gaining popularity in recent years, they are hardly covered in the literature for the ball-on-sphere system. To the best of the researcher's knowledge, [19] was the first to design an optimal LQR for the ball-on-sphere system. But adaptive feedback linearization control has been covered for the system. Based on the recent review of the literature, the researcher did not come across an LQG design for the ball-on-sphere system.

To address the above-mentioned issue (lack of LQG controller design and comparative analysis of LQR and LQG controllers for the ball-on-sphere system in the literature), the research designed optimal LQR and LQG controllers for the system of ball-on-sphere and did a comparative analysis between the two. Specifically, the research derived the dynamical equations and state space of the system, designed the controllers, and compared their performance.

The paper aims to do a comparative analysis of the LQR and LQG controllers for the ball-on-sphere system.

The major research objectives relevant to the research aim are

- To investigate the dynamics and derive the mathematical model of the system.

- To linearize the system due to its nonlinear nature.

- To derive the state space representation of the system.

- To design optimal LQR and LQG controllers by finding the relevant matrices using the trial and error method.

- To analyze and compare the performance of the two controllers for the system.

No particular method can be argued to be the best because every method has its advantages and disadvantages. The limitation of this research is that the controllers are linear while the system is nonlinear. Therefore, the linearized system gives a minimum workable system.

Broadly speaking, the research aims to achieve an at least $80 \%$ settling time less than unregulated settling time of the ball's angle with respect to both $x$ and $y$ directions, zero overshoot of the ball's angles, and all angles should settle to zero or remain very close to zero.

\section{Literature Review}

[20] obtained the magnetic levitation (MagLev) system's nonlinear representation and the representation was linearized about its equilibrium point. Proportion integral derivative (PID) and LQR controllers' gains were also derived. The approach performance was, finally, investigated using simulation. The obtained results showed that the control scheme stabilizes the ball position. It was also observed that there was significant disturbance rejection. PID and LQR performances were also examined and compared.

Aircraft lateral flight dynamics are controlled in [21] using LQR and linear feedback (LF) techniques. Due to the linear nature of the controllers, the system was linearized. Poles were placed using a pole placement scheme. Placing the poles at the location of interest finds the LF controller's feedback gain matrix, $\mathbf{K}$, and stabilizes the controller's response. To find $\mathbf{K}$ using the LQR scheme, appropriate $\mathbf{Q}$ and $\mathbf{R}$ matrices were chosen. The lateral dynamics responses, i.e. yaw rate, slide slip angle, roll angle, and roll rate, were analyzed. Lastly, the 2 controllers' performances were compared.

A system of an inverted pendulum (IP) is stabilized in [22] using state-based observer optimal LQG control. Based on the separation principle, first, all system states were assumed not to be fully measurable, and measurement and process noises corrupted the system thereby designing the Kalman filter. Then, a state feedback controller was designed by obtaining the control law.

The designed controller was then simulated. From the results obtained, it was observed that measurement and process noises were eliminated and the controller stabilized the system.

Double inverted pendulum (DIP)-cart system dynamics are modelled and mathematically represented in [23] where a control strategy with disturbance input is used using LQR and PID. A feedback control was used to obtain the LQR controller and the system states were given this controller. The control scheme's simulation was done using matrix laboratory (MATLAB)/SIMULINK. Performance analysis of the 2 controllers for the DIP-cart system and doing a 
comparative study was the work's aim. The results proved that the LQR control scheme performs better than the PID control scheme.

Robustness and closed-loop performance are determined by the choice of $\mathbf{Q}$ and $\mathbf{R}$ matrices in the design of optimal LQG control. It is a well-known fact that a system like an electro-pneumatic actuator is difficult to control. Based on the existing literature, [24] developed the LQG synthesis methodology and applied it to this system.

Kalman filter and LQR were designed in [25] by taking, system performance and measurement and random system noises, into consideration. Therefore, the controller is an LQG. Then, internal model control (IMC) controller was also integrated. The simulation results showed that parameter variation influence can be dealt with by this method. Good stability and strong robustness were also observed. The proposed strategy is suitable for engineering applications and is easy to regulate.

An LQR controller systematic design is presented in [26], which has an integral action. The controller was used to control direct current (DC)/DC converter topology. Based on the energy considerations, $\mathbf{Q}$ and $\mathbf{R}$ matrices were selected. Then, for state estimation and filtering purposes, Kalman filter was designed to have an LQG controller.

A converter's state-space model, which has non-ideal elements, was then developed for the LQG controller's proper operation. A discrete-time domain simulation, showing the robustness of the 2 controllers, was presented. LQR's test results carried out in a laboratory were also shown.

Ball's position on a beam was controlled using an LQR designed and simulated in [27]. The control was done by changing the beam's angular position. Observer-based state feedback, since not all the system states are measurable, was applied. The LQR scheme modelling as well as simulation to control the system was done with the help of MATLAB/SIMULINK. The LQR scheme effectively stabilized the system with the sensor noises' effect in simulation. LQG and LQR performances were comparatively analyzed.

[28] presented basic theory related to LQG and LQR controllers' design process. Tests were carried out for performance evaluation of a digital autopilot using an LQG/LQR controller. The tests considered stability requirements and different performance criteria given by the regulatory agencies. An aircraft simulation model was used to test the robustness of the design.

By considering the friction effect, [7] outlined the ball-on-sphere system's analysis model. The bond graph technique was used to model the system. Based on the technique, proper causality assignment of dissipating elements, various subsystems, transformer elements, junction structures, storage elements, and energy exchange that make the system up were located and modelled.

\section{System's Mathematical Modelling and Dynamics}

One of the important parts of the control system design process is the modelling or representing the system. To design and analyze controllers, understanding the physical system is a requirement. An accurate dynamical system's representation or model helps us in this understanding. Differential equations describe the dynamical systems' behaviour. Deriving these equations, from the laws of physics, is among the first design process stages. There are different methods of deriving these equations. The Newtonian and Lagrangian methods are the two most commonly used methods for mechanical systems. Ideally, these methods should give the same results. But the system's nature determines which of the methods is simpler for that particular system. Because the dynamic equations, of the ball-onsphere system, are highly nonlinear and coupled, it is difficult to find the significant dynamics of the system. Therefore, dynamical equations are derived by adopting the system's representation or model [29]-[30]. System's parameters: $R$ and $r$, which are the sphere and ball radii respectively, $m$ is the ball mass, $I_{B}$ and $I_{b}$, which are the sphere and ball inertia moments respectively, $\theta_{y}, \beta_{y}$, which are the ball and sphere angles with respect to $y-$ direction respectively, $\theta_{x}, \beta_{x}$, which are the ball and sphere angles with respect to $x$-direction respectively [31]. The system's schema in 2$\mathrm{D}$ is shown in Fig. 1. while Fig. 2. shows the ball-on-sphere system in 3-D.

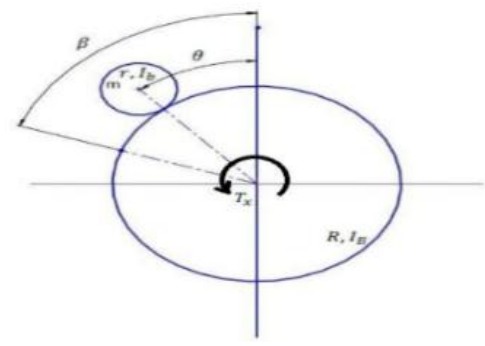

Fig. 1. System's schema in 2-D [32]. 


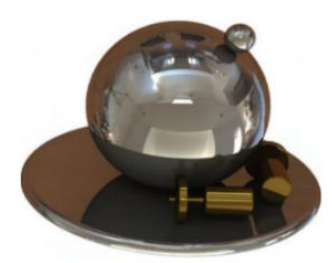

Fig. 2. System of ball-on-sphere [31].

The Lagrangian method is used in deriving the equations as follows [33]:

$$
L=T-V
$$

where $V, T$, and $L$ are the potential and kinetic energy, and the Lagrangian respectively.

$$
\frac{\partial}{\partial t}\left(\frac{\partial L}{\partial \dot{q}}\right)-\frac{\partial L}{\partial q}=Q_{i}, \quad i=1,2,3,4
$$

where $q$ and $Q$ are the generalized coordinate and torque, respectively.

With these assumptions [32]

$$
\begin{gathered}
\left\{\begin{array}{c}
Q_{1}=0 \\
Q_{2}=T_{x} \\
Q_{3}=0 \\
Q_{4}=T_{y}
\end{array}\right. \\
q=\left[\begin{array}{llll}
\theta_{x} & \beta_{x} & \theta_{y} & \beta_{y}
\end{array}\right]^{\mathrm{T}}
\end{gathered}
$$

- The ball is rolling, with no slipping, on the sphere.

- The sphere and ball are in contact always

- No friction effect

and from the linearized model with respect to the equilibrium point, the system can be decoupled into the following two independent subsystems

$$
\begin{gathered}
\left((R+r) m+I_{b} \frac{R+r}{r^{2}}\right) \ddot{\theta}_{x}+\left(-I_{b} \frac{R}{r^{2}}\right) \ddot{\beta}_{x}-m g \sin \left(\theta_{x}\right)=0 \\
\left(-I_{b} \frac{R(R+r)}{r^{2}}\right) \ddot{\theta}_{x}+\left(I_{B}+I_{b} \frac{R^{2}}{r^{2}}\right) \ddot{\beta}_{x}=T_{x} \\
\left((R+r) m+I_{b} \frac{R+r}{r^{2}}\right) \ddot{\theta}_{y}+\left(-I_{b} \frac{R}{r^{2}}\right) \ddot{\beta}_{y}-m g \sin \left(\theta_{y}\right)=0 \\
\left(-I_{b} \frac{R(R+r)}{r^{2}}\right) \ddot{\theta}_{y}+\left(I_{B}+I_{b} \frac{R^{2}}{r^{2}}\right) \ddot{\beta}_{y}=T_{y}
\end{gathered}
$$

Thus, near the equilibrium point, the system can be separated into 2 independent systems of ball and wheel. These subsystems are independently treated and controlled by a controller individually in the $x$ and $y$ directions [32].

The system has 8 state variables because each of the 4 differential equations, (5) - (8), is of the second order. State variables are:

$$
\left\{\begin{array}{l}
x_{1}=\theta_{x} \\
x_{2}=\dot{\theta}_{x} \\
x_{3}=\beta_{x} \\
x_{4}=\dot{\beta}_{x} \\
x_{5}=\theta_{y} \\
x_{6}=\dot{\theta}_{y} \\
x_{7}=\beta_{y} \\
x_{8}=\dot{\beta}_{y}
\end{array}\right.
$$


Taking the derivative of equation (9) and using equation (4) we then get the following equation

$$
\left\{\begin{array}{l}
\dot{x}_{1}=x_{2} \\
\dot{x}_{2}=\ddot{q}_{1} \\
\dot{x}_{3}=x_{4} \\
\dot{x}_{4}=\ddot{q}_{2} \\
\dot{x}_{5}=x_{6} \\
\dot{x}_{6}=\ddot{q}_{3} \\
\dot{x}_{7}=x_{8} \\
\dot{x}_{8}=\ddot{q}_{4}
\end{array}\right.
$$

Assuming $\theta_{x}, \beta_{x}, \theta_{y}$ and $\beta_{y}, T_{x}$ and $T_{y}$ to be the system's outputs and inputs respectively. By arbitrarily naming the state variables, we get

$$
\left\{\begin{array}{l}
x_{1}=\theta_{x} \\
x_{2}=\beta_{x} \\
x_{3}=\theta_{y} \\
x_{4}=\beta_{y} \\
x_{5}=\dot{\theta}_{x} \\
x_{6}=\dot{\beta}_{x} \\
x_{7}=\dot{\theta}_{y} \\
x_{8}=\dot{\beta}_{y}
\end{array}\right.
$$

We get, from equation (11), the first 4 state equations as;

$$
\begin{aligned}
& \dot{x}_{1}=x_{5} \\
& \dot{x}_{2}=x_{6} \\
& \dot{x}_{3}=x_{7} \\
& \dot{x}_{4}=x_{8}
\end{aligned}
$$

By taking $\theta$ and $\beta$ at the equilibrium point to be small, the system can be linearized [34]. This is to $\operatorname{say,} \sin (\theta)=$ $\theta, \cos (\theta)=1, \sin (\beta)=\beta$, and $\cos (\beta)=1$.

Then substituting these assumptions into equations (5) - (8) gives;

$$
\begin{gathered}
a \ddot{\theta}_{x}+b \ddot{\beta}_{x}-m g \theta_{x}=0 \\
c \ddot{\theta}_{x}+d \ddot{\beta}_{x}=T_{x} \\
a \ddot{\theta}_{y}+b \ddot{\beta}_{y}-m g \theta_{y}=0 \\
c \ddot{\theta}_{y}+d \ddot{\beta}_{y}=T_{y}
\end{gathered}
$$

where

$$
\left\{a=\left((R+r) m+I_{b} \frac{R+r}{r^{2}}\right), b=\left(-I_{b} \frac{R}{r^{2}}\right), c=\left(-I_{b} \frac{R(R+r)}{r^{2}}\right), d=\left(I_{B}+I_{b} \frac{R^{2}}{r^{2}}\right)\right.
$$

The 4 remaining state equations can then be expressed as

$$
\begin{gathered}
\dot{x}_{5}=v x_{1}-w T_{x} \\
\dot{x}_{6}=z x_{1}-e T_{x}
\end{gathered}
$$




$$
\begin{aligned}
& \dot{x}_{7}=v x_{3}-w T_{y} \\
& \dot{x}_{8}=z x_{3}-e T_{y}
\end{aligned}
$$

where

$$
\left\{v=\frac{d m g}{a d-b c}, \quad w=\frac{b}{a d-b c}, \quad z=\frac{c m g}{b c-a d}, \quad e=\frac{a}{b c-a d}\right.
$$

In matrix form,

$$
\left[\begin{array}{l}
\dot{x}_{1} \\
\dot{x}_{2} \\
\dot{x}_{3} \\
\dot{x}_{4} \\
\dot{x}_{5} \\
\dot{x}_{6} \\
\dot{x}_{7} \\
\dot{x}_{8}
\end{array}\right]=\left[\begin{array}{llllllll}
0 & 0 & 0 & 0 & 1 & 0 & 0 & 0 \\
0 & 0 & 0 & 0 & 0 & 1 & 0 & 0 \\
0 & 0 & 0 & 0 & 0 & 0 & 1 & 0 \\
0 & 0 & 0 & 0 & 0 & 0 & 0 & 1 \\
v & 0 & 0 & 0 & 0 & 0 & 0 & 0 \\
z & 0 & 0 & 0 & 0 & 0 & 0 & 0 \\
0 & 0 & v & 0 & 0 & 0 & 0 & 0 \\
0 & 0 & z & 0 & 0 & 0 & 0 & 0
\end{array}\right]\left[\begin{array}{l}
x_{1} \\
x_{2} \\
x_{3} \\
x_{4} \\
x_{5} \\
x_{6} \\
x_{7} \\
x_{8}
\end{array}\right]+\left[\begin{array}{cc}
0 & 0 \\
0 & 0 \\
0 & 0 \\
0 & 0 \\
-w & 0 \\
-e & 0 \\
0 & -w \\
0 & -e
\end{array}\right]\left[\begin{array}{c}
T_{x} \\
T_{y}
\end{array}\right]
$$

The output equations are;

$$
\begin{aligned}
& \theta_{x}=x_{1} \\
& \beta_{x}=x_{2} \\
& \theta_{y}=x_{3} \\
& \beta_{y}=x_{4}
\end{aligned}
$$

In matrix form,

Then the coefficient matrices are;

$$
\left[\begin{array}{l}
\theta_{x} \\
\beta_{x} \\
\theta_{y} \\
\beta_{y}
\end{array}\right]=\left[\begin{array}{llllllll}
1 & 0 & 0 & 0 & 0 & 0 & 0 & 0 \\
0 & 1 & 0 & 0 & 0 & 0 & 0 & 0 \\
0 & 0 & 1 & 0 & 0 & 0 & 0 & 0 \\
0 & 0 & 0 & 1 & 0 & 0 & 0 & 0
\end{array}\right]\left[\begin{array}{l}
x_{1} \\
x_{2} \\
x_{3} \\
x_{4} \\
x_{5} \\
x_{6} \\
x_{7} \\
x_{8}
\end{array}\right]+\left[\begin{array}{ll}
0 & 0 \\
0 & 0 \\
0 & 0 \\
0 & 0
\end{array}\right]\left[\begin{array}{l}
T_{x} \\
T_{y}
\end{array}\right]
$$

$$
\begin{aligned}
\mathbf{A} & =\left[\begin{array}{llllllll}
0 & 0 & 0 & 0 & 1 & 0 & 0 & 0 \\
0 & 0 & 0 & 0 & 0 & 1 & 0 & 0 \\
0 & 0 & 0 & 0 & 0 & 0 & 1 & 0 \\
0 & 0 & 0 & 0 & 0 & 0 & 0 & 1 \\
v & 0 & 0 & 0 & 0 & 0 & 0 & 0 \\
z & 0 & 0 & 0 & 0 & 0 & 0 & 0 \\
0 & 0 & v & 0 & 0 & 0 & 0 & 0 \\
0 & 0 & z & 0 & 0 & 0 & 0 & 0
\end{array}\right] \\
\mathbf{B} & =\left[\begin{array}{ccc}
0 & 0 \\
0 & 0 \\
0 & 0 \\
0 & 0 \\
-w & 0 \\
-e & 0 \\
0 & -w \\
0 & -e
\end{array}\right]
\end{aligned}
$$




$$
\begin{gathered}
\mathbf{C}=\left[\begin{array}{llllllll}
1 & 0 & 0 & 0 & 0 & 0 & 0 & 0 \\
0 & 1 & 0 & 0 & 0 & 0 & 0 & 0 \\
0 & 0 & 1 & 0 & 0 & 0 & 0 & 0 \\
0 & 0 & 0 & 1 & 0 & 0 & 0 & 0
\end{array}\right] \\
\mathbf{D}=\left[\begin{array}{ll}
0 & 0 \\
0 & 0 \\
0 & 0 \\
0 & 0
\end{array}\right]
\end{gathered}
$$

\section{Design of Controllers}

\section{LQR}

State-space representation is used in designing the LQR, full state feedback, controller which gives an optimal control. The controller multiplies a gain matrix by the fed full state vector and this is subtracted from the scale reference.

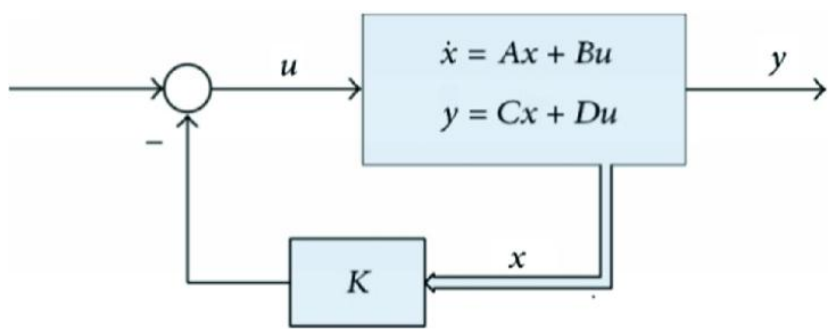

Fig. 3. The LQR control system structure.

By selecting closed-loop characteristics, suitable to our desired design, the optimal $\mathbf{K}$ can be found in the LQR design. Particularly, to what extent the system performs and what effort it takes to achieve that performance.

Given the system's dynamics

$$
\begin{array}{r}
\dot{\mathbf{x}}=\mathbf{A x}+\mathbf{B u} \\
\mathbf{y}=\mathbf{C x}+\mathbf{D u}
\end{array}
$$

Using a cost function

$$
J=\int_{0}^{\infty}\left(\mathbf{x}^{\mathrm{T}} \mathbf{Q} \mathbf{x}+\mathbf{u}^{\mathrm{T}} \mathbf{R} \mathbf{u}\right) \mathrm{d} t
$$

the optimal gain matrix is found by the LQR control.

Choosing $\mathbf{R}$ and $\mathbf{Q}$ as diagonal matrices is the conventional and practicable method of choice.

The lowest cost is provided by the gain matrix when the LQR problem is solved. Then,

$$
\mathbf{u}=-\mathbf{K x}
$$

where $\mathbf{K}$

$$
\mathbf{K}=\mathbf{R}^{-1} \mathbf{B}^{\mathrm{T}} \mathbf{P}
$$

$\mathbf{P}$ can be found by solving the Riccati equation

$$
\mathbf{A}^{\mathrm{T}} \mathbf{P}+\mathbf{P A}-\mathbf{P B R}^{-1} \mathbf{B}^{\mathrm{T}} \mathbf{P}+\mathbf{Q}=0
$$

Adjusting R, penalizes the actuator effort while adjusting $\mathbf{Q}$ penalizes bad performance. Input vector judges actuator effort while state vector judges performance.

\section{LQG}

Two stages of design are involved in the LQG controller design 
- $\quad$ LQ Controller (LQR) design

- LQ Estimator (Kalman filter) design

After designing them separately, then they are combined to form the LQG controller.

The purpose of LQG design is to control systems and the design follows the separation principle.

An optimal prediction-correction estimation is implemented by the Kalman filter, which is basically a mathematical set of equations. It is optimal because the estimated error covariance is minimized when some assumed conditions are satisfied [35].

Fig. 4. shows the Kalman filter used as an optimal observer while Fig. 5. shows the LQG regulator.

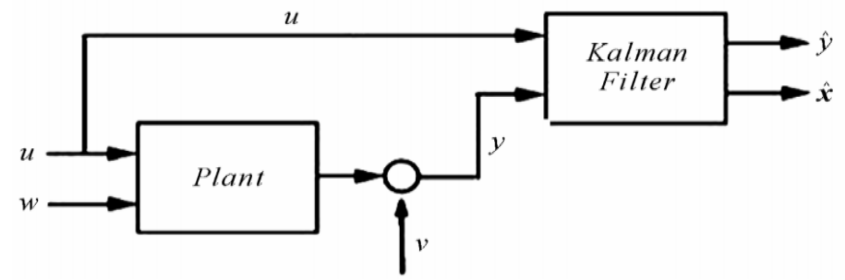

Fig. 4. Kalman filter used as an optimal observer [36].

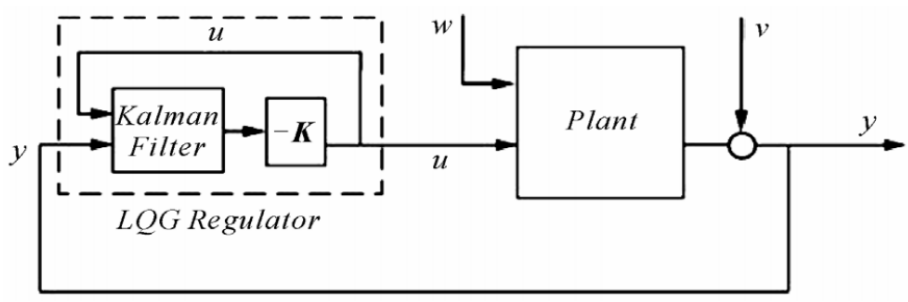

Fig. 5. LQG regulator [36].

A collection of recursive equations plus the system's discrete model is what the Kalman filter's general form usually contains. $\mathbf{P}$, system covariance matrix, and $\mathbf{L}$, Kalman gain matrix are continuously updated by these recursive equations [37].

From a collection of recursive equations, $\mathbf{L}$ can be obtained. These recursive equations start from some starting covariance matrix $\mathbf{P}(k / k)$

$$
\begin{gathered}
\mathbf{P}(k+1 / k)=\mathbf{A}(T) \mathbf{P}(k / k) \mathbf{A}^{\mathrm{T}}(T)+\mathbf{C}_{\mathrm{d}}(T) \mathbf{Q}_{\mathrm{e}} \mathbf{C}_{\mathrm{d}}^{\mathrm{T}}(T) \\
\mathbf{L}(k+1)=\mathbf{P}(k+1 / k) \mathbf{C}^{\mathrm{T}}(T)\left\{\mathbf{C}(T) \mathbf{P}(k+1 / k) \mathbf{C}^{\mathrm{T}}(T)+\mathbf{R}_{\mathrm{e}}\right\}^{-1} \\
\mathbf{P}(k+1 / k+1)=\{\mathbf{I}-\mathbf{L}(k+1) \mathbf{C}(T)\} \mathbf{P}(k+1 / k)
\end{gathered}
$$

The process goes on by putting the covariance $\mathbf{P}(k+1 / k+1)$, (42), back into equation (40) as $\mathbf{P}(k / k)$ till $\mathbf{L}(k+1)$ goes to a steady value.

Here, $\mathbf{C}_{\mathrm{d}}(T), \mathbf{R}_{\mathrm{e}}$, and $\mathbf{Q}_{\mathrm{e}}$ are the disturbance transition, measurement noise covariance, and disturbance noise covariance matrices, respectively.

Let $\mathbf{P}(k / k)=\mathbf{P}_{1}, \mathbf{P}(k+1 / k+1)=\mathbf{P}_{3}$, and $\mathbf{P}(k+1 / k)=\mathbf{P}_{2}$, then equations (40) - (42) become

$$
\begin{gathered}
\mathbf{P}_{2}=\mathbf{A P}_{1} \mathbf{A}^{\mathrm{T}}+\mathbf{C}_{\mathrm{d}} \mathbf{Q}_{\mathrm{e}} \mathbf{C}_{\mathrm{d}}^{\mathrm{T}} \\
\mathbf{L}=\mathbf{P}_{2} \mathbf{C}^{\mathrm{T}}\left\{\mathbf{C} \mathbf{P}_{2} \mathbf{C}^{\mathrm{T}}+\mathbf{R}_{\mathrm{e}}\right\}^{-1} \\
\mathbf{P}_{3}=\{\mathbf{I}-\mathbf{L} \mathbf{C}\} \mathbf{P}_{2}
\end{gathered}
$$




\section{Results and Analysis}

The regulation was done based on the following system performance:

- The ball's angle with respect to both $x$ and $y$ directions should have at least $80 \%$ settling time less than its unregulated settling time.

- The ball's angles should have zero overshoot.

- All angles should settle to zero or remain very close to zero.

The system's physical parameters were given arbitrary values for the sake of controlling the system. These are presented in Table 1.

Table 1. Desired system's physical parameters [38].

\begin{tabular}{|c|c|c|}
\hline Parameter & Value & Units \\
\hline Mass of the ball $(m)$ & 0.06000 & $\mathrm{~kg}$ \\
\hline The radius of the ball $(r)$ & 0.01250 & $\mathrm{~m}$ \\
\hline The radius of the sphere $(R)$ & 0.15000 & $\mathrm{~m}$ \\
\hline Ball's moment of inertia $\left(I_{b}\right)$ & $3.75 \times 10^{-6}$ & $\mathrm{~kg} \cdot \mathrm{m}^{2}$ \\
\hline Sphere's moment of inertia $\left(I_{B}\right)$ & 0.99 & $\mathrm{~kg} \cdot \mathrm{m}^{2}$ \\
\hline Gravitational acceleration $(g)$ & 9.81 & $\mathrm{~m} / \mathrm{s}^{2}$ \\
\hline
\end{tabular}

The system, system states, was assigned desired initial conditions, and this assignment is done arbitrarily. These are presented in Table 2.

Table 2. System's desired initial conditions [38].

\begin{tabular}{|c|c|c|}
\hline Initial parameter & Value & Units \\
\hline$\theta_{x 0}$ & 0.07 & $\mathrm{rad}$ \\
\hline$\beta_{x 0}$ & 0 & $\mathrm{rad}$ \\
\hline$\theta_{y 0}$ & 0.07 & $\mathrm{rad}$ \\
\hline$\beta_{y 0}$ & 0 & $\mathrm{rad}$ \\
\hline$\dot{\theta}_{x 0}$ & 0.02 & $\mathrm{rad} / \mathrm{s}$ \\
\hline$\dot{\beta}_{x 0}$ & 0 & $\mathrm{rad} / \mathrm{s}$ \\
\hline$\dot{\theta}_{y 0}$ & 0.05 & $\mathrm{rad} / \mathrm{s}$ \\
\hline$\dot{\beta}_{y 0}$ & 0 & $\mathrm{rad} / \mathrm{s}$ \\
\hline
\end{tabular}

Based on the system's physical parameters presented in Table 1., the coefficient matrices have the following numerical values:

$$
\begin{gathered}
\mathbf{A}=\left[\begin{array}{cccccccc}
0 & 0 & 0 & 0 & 1 & 0 & 0 & 0 \\
0 & 0 & 0 & 0 & 0 & 1 & 0 & 0 \\
0 & 0 & 0 & 0 & 0 & 0 & 1 & 0 \\
0 & 0 & 0 & 0 & 0 & 0 & 0 & 1 \\
43.1276 & 0 & 0 & 0 & 0 & 0 & 0 & 0 \\
0.0255 & 0 & 0 & 0 & 0 & 0 & 0 & 0 \\
0 & 43.1276 & 0 & 0 & 0 & 0 & 0 & 0 \\
0 & 0.0255 & 0 & 0 & 0 & 0 & 0 & 0
\end{array}\right] \quad \mathbf{B}=\left[\begin{array}{ccc}
0 & 0 \\
0 & 0 \\
0 & 0 \\
0 & 0 \\
0.2663 & 0 \\
1.0097 & 0 \\
0 & 0.2663 \\
0 & 1.0097
\end{array}\right] \\
\mathbf{C}=\left[\begin{array}{llllllll}
1 & 0 & 0 & 0 & 0 & 0 & 0 & 0 \\
0 & 1 & 0 & 0 & 0 & 0 & 0 & 0 \\
0 & 0 & 1 & 0 & 0 & 0 & 0 & 0 \\
0 & 0 & 0 & 1 & 0 & 0 & 0 & 0
\end{array}\right] \quad \mathbf{D}=\left[\begin{array}{ll}
0 & 0 \\
0 & 0 \\
0 & 0 \\
0 & 0
\end{array}\right]
\end{gathered}
$$

\section{LQR}

Given the arbitrarily chosen desired initial conditions in Table 2., the inputs to the system have in $x$ - direction a maximum of $30.5 \mathrm{Joule} / \mathrm{rad}$ and a minimum of $-3.856 \mathrm{Joule} / \mathrm{rad}$, and in the $y-$ direction is a maximum and a minimum of $32.4 \mathrm{Joule} / \mathrm{rad}$ and $-4.097 \mathrm{Joule} / \mathrm{rad}$ respectively. These responses are shown in Fig. 6. and Fig. 7. Given that the angular velocity along the $x$-direction is $0.02 \mathrm{rad} / \mathrm{s}$, which is smaller than $0.05 \mathrm{rad} / \mathrm{s}$ along the $y$ - direction, it can be observed that the higher the angular velocity the higher the input (torque). Angular velocity is directly proportional to the input. The settling time of the input in the $x$-direction is about 5.90 sec while in the 
$y$ - direction is about $6.00 \mathrm{sec}$.

The settling time in the $x$-direction is less than that of the $y$-direction, which implies that settling time is also directly proportional to the input.

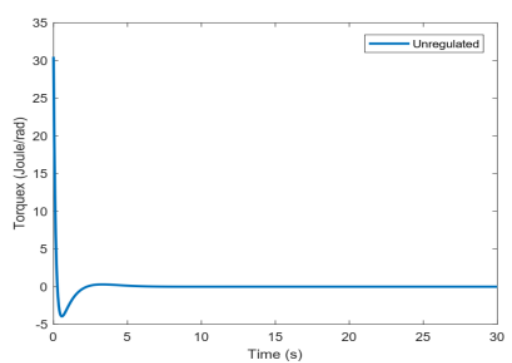

Fig. 6. LQR unregulated input response in the $x$ - direction, $T_{x}$.

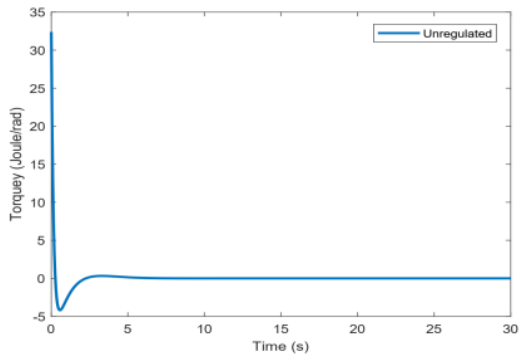

Fig. 7. $\mathrm{LQR}$ unregulated input response in the $y$ - direction, $T_{y}$.

Fig. 8. and Fig. 9. show output responses, $\theta_{x}$ and $\theta_{y}$, which are the ball's angles with respect to $x$ and $y$ directions respectively, both have a settling time of about $7.00 \mathrm{sec}$. For smaller angular velocities, it was found out that the settling time of the ball's angle is almost independent of the angular velocity. It can also be noted that different input values of the $x$ and $y$ directions give the same settling time in both directions.

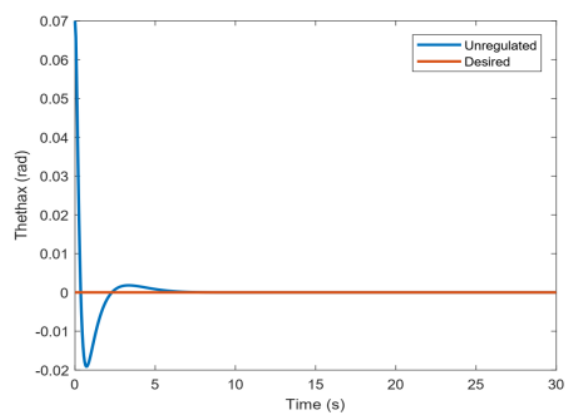

Fig. 8. LQR unregulated output response in the $x$ - direction, $\theta_{x}$.

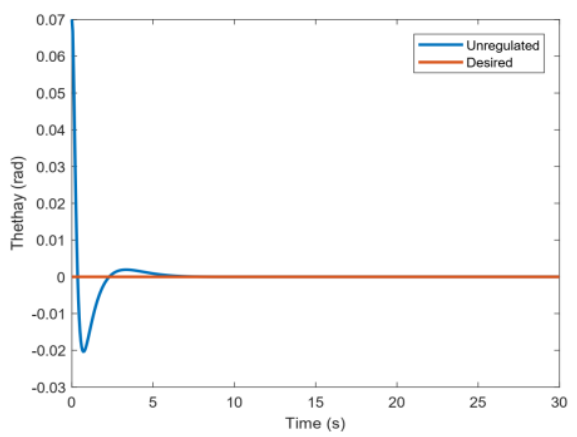

Fig. 9. LQR unregulated output response in the $y-$ direction, $\theta_{y}$. 
For the output response, $\beta_{x}$, which is the sphere's angle with respect to the $x$ - direction, and $\beta_{y}$, which is the sphere's angle with respect to $y$ - direction, the settling time is about $7.10 \mathrm{sec}$ and $7.00 \mathrm{sec}$ respectively. $\beta_{y}$ settles faster than $\beta_{x}$. Since the main purpose is not to "directly" control the sphere, the relationship between angular velocity and settling time was not checked. The input was only applied to the ball. These responses are shown in Fig. 10. and Fig. 11.

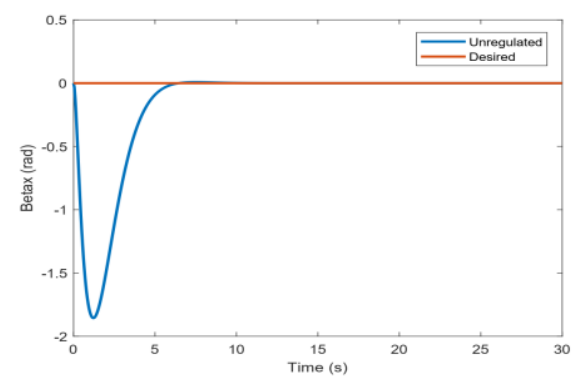

Fig. 10. LQR unregulated output response in the $x$ - direction, $\beta_{x}$.

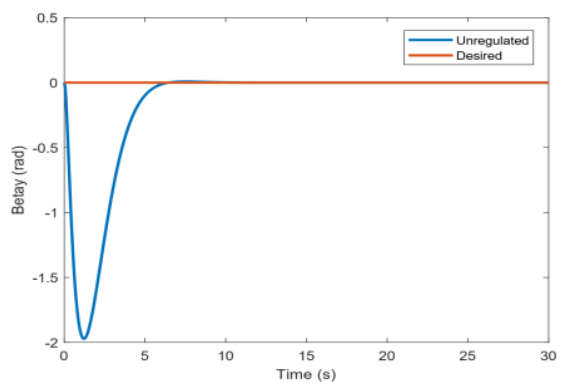

Fig. 11. LQR unregulated output response in the $y-$ direction, $\beta_{y}$.

The matrices that give these unregulated responses in Fig. 6. through Fig. 11. are as below. It is important to note that all matrices to be manipulated, such as $\mathbf{Q}$ and $\mathbf{R}$ matrices, were initially taken to be identity matrices and this is per the conventional practice.

$$
\begin{aligned}
& \mathbf{Q}=\left[\begin{array}{llllllll}
1 & 0 & 0 & 0 & 0 & 0 & 0 & 0 \\
0 & 1 & 0 & 0 & 0 & 0 & 0 & 0 \\
0 & 0 & 1 & 0 & 0 & 0 & 0 & 0 \\
0 & 0 & 0 & 1 & 0 & 0 & 0 & 0 \\
0 & 0 & 0 & 0 & 1 & 0 & 0 & 0 \\
0 & 0 & 0 & 0 & 0 & 1 & 0 & 0 \\
0 & 0 & 0 & 0 & 0 & 0 & 1 & 0 \\
0 & 0 & 0 & 0 & 0 & 0 & 0 & 1
\end{array}\right] \quad \mathbf{R}=\left[\begin{array}{ll}
1 & 0 \\
0 & 1
\end{array}\right] \quad \mathbf{E}=\left[\begin{array}{l}
-6.7017+0.0000 \mathrm{i} \\
-6.7017+0.0000 \mathrm{i} \\
-6.4354+0.0000 \mathrm{i} \\
-6.4354+0.0000 \mathrm{i} \\
-0.8715+0.5000 \mathrm{i} \\
-0.8715-0.5000 \mathrm{i} \\
-0.8715+0.5000 \mathrm{i} \\
-0.8715-0.5000 \mathrm{i}
\end{array}\right] \\
& \mathbf{K}=\left[\begin{array}{cccccccc}
417.4791 & -1.0000 & -0.0000 & 0.0000 & 63.5795 & -2.0312 & -0.0000 & 0.0000 \\
-0.0000 & 0.0000 & 417.4791 & -1.0000 & -0.0000 & 0.0000 & 63.5795 & -2.0312
\end{array}\right] \\
& \mathbf{P}=10^{4}\left[\begin{array}{cccccccc}
1.3272 & -0.0064 & -0.0000 & 0.0000 & 0.2021 & -0.0119 & -0.0000 & 0.0000 \\
-0.0064 & 0.0002 & 0.0000 & -0.0000 & -0.0010 & 0.0002 & 0.0000 & -0.0000 \\
-0.0000 & 0.0000 & 1.3272 & -0.0064 & -0.0000 & 0.0000 & 0.2021 & -0.0119 \\
0.0000 & -0.0000 & -0.0064 & 0.0002 & 0.0000 & -0.0000 & -0.0010 & 0.0002 \\
0.2021 & -0.0010 & -0.0000 & 0.0000 & 0.0308 & -0.0018 & -0.0000 & 0.0000 \\
-0.0119 & 0.0002 & 0.0000 & -0.0000 & -0.0018 & 0.0003 & 0.0000 & -0.0000 \\
-0.0000 & 0.0000 & 0.2021 & -0.0010 & -0.0000 & 0.0000 & 0.0308 & -0.0018 \\
0.0000 & -0.0000 & -0.0119 & 0.0002 & 0.0000 & -0.0000 & -0.0018 & 0.0003
\end{array}\right]
\end{aligned}
$$

Here $\mathbf{Q}$ is the state weighting matrix that controls the total transient energy, $\mathbf{R}$ is the control (input) matrix that controls the total control energy, $\mathbf{K}$ is the state feedback gain matrix, $\mathbf{P}$ is the Riccati matrix, and $\mathbf{E}$ is the closed-loop eigenvalues that indicate poles position.

When the $\mathbf{Q}$ and $\mathbf{R}$ matrices were regulated to get the desired system performance, two of the many inputs that meet the desired performance were found to have $31.0 \mathrm{Joule} / \mathrm{rad}$ and $44.2 \mathrm{Joule} / \mathrm{rad}$ in $x$ and $y$ directions, respectively, with a settling time of $0.75 \mathrm{sec}$ for $T_{x}$ and $0.70 \mathrm{sec}$ for $T_{y}$. The relationship between input and settling 
time, as well as input and angular velocity, cannot be deduced since many inputs can satisfy the desired system performance. The regulated input responses are shown in Fig. 12. and Fig. 13.

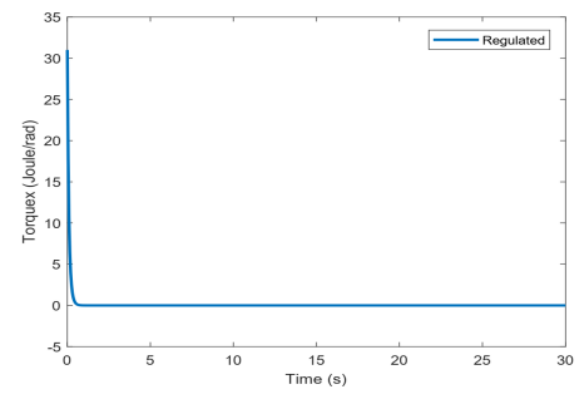

Fig. 12. LQR regulated input response in the $x$ - direction, $T_{x}$.

After regulating the controller according to the system performance, two of the possible output responses have a settling time of $0.90 \mathrm{sec}$ and $0.95 \mathrm{sec}$ for $\theta_{x}$ and $\theta_{y}$, respectively. For $\theta_{x}$, the $0.90 \mathrm{sec}$ settling time is $12.86 \%$ of its unregulated settling time which is $7.0 \mathrm{sec}$ (Fig. 8.). This means that $\theta_{x}$ has a settling time $87.14 \%$ less than its unregulated. While for $\theta_{y}$, the $0.95 \mathrm{sec}$ settling time means it has $86.43 \%$ less than its unregulated settling time (Fig. 9.). The regulated output responses are shown in Fig. 14. and Fig. 15.

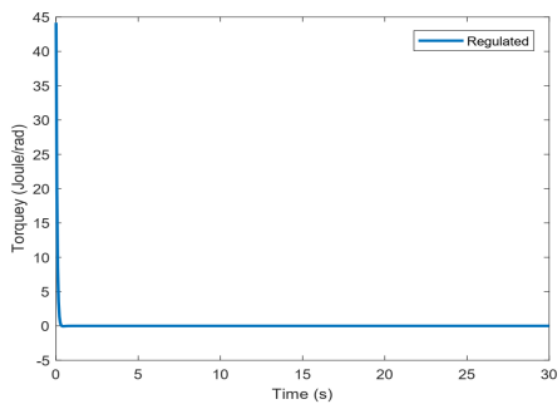

Fig. 13. LQR regulated input response in the $y-$ direction, $T_{y}$.

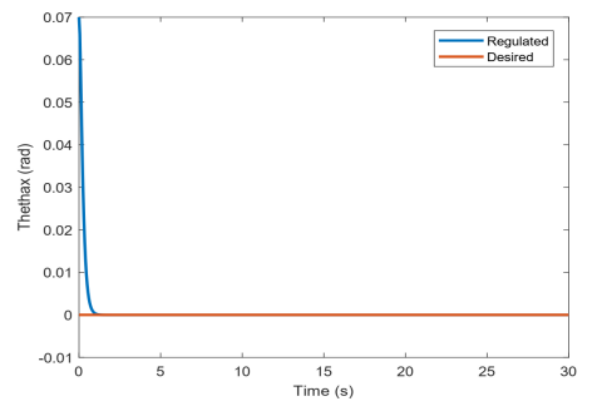

Fig. 14. LQR regulated output response in the $x$ - direction, $\theta_{x}$.

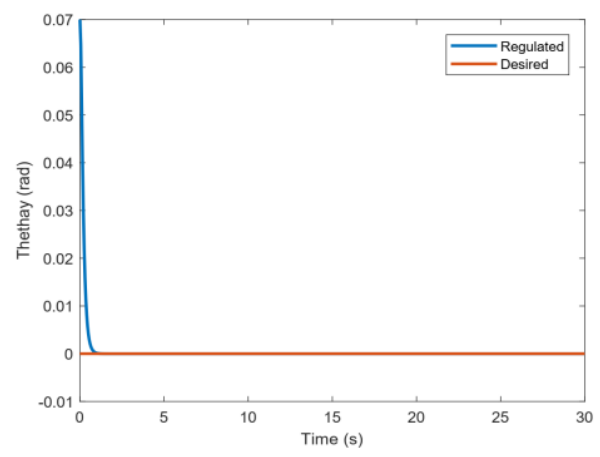

Fig. 15. LQR regulated output response in the $y-$ direction, $\theta_{y}$. 
Fig. 16. and Fig. 17. show the regulated output responses $\beta_{x}$ and $\beta_{y}$.

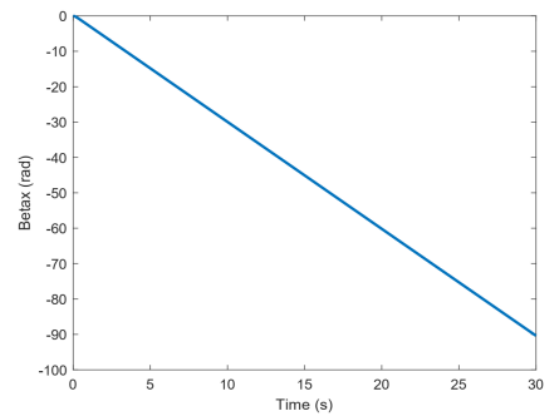

Fig. 16. LQR regulated output response in the $x$ - direction, $\beta_{x}$.

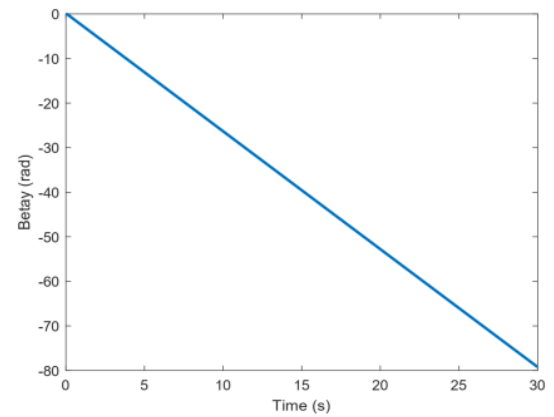

Fig. 17. LQR regulated output response in the $y-$ direction, $\beta_{y}$.

The regulated system matrices are as below. From this set of matrices, which are one possible set, it can be observed that all the states play role in regulating the system to the desired system performance.

$$
\begin{gathered}
\mathbf{Q}=10^{-4}\left[\begin{array}{cccccccc}
1 & 0 & 0 & 0 & 0 & 0 & 0 & 0 \\
0 & 1 & 0 & 0 & 0 & 0 & 0 & 0 \\
0 & 0 & 1 & 0 & 0 & 0 & 0 & 0 \\
0 & 0 & 0 & 1 & 0 & 0 & 0 & 0 \\
0 & 0 & 0 & 0 & 1 & 0 & 0 & 0 \\
0 & 0 & 0 & 0 & 0 & 1 & 0 & 0 \\
0 & 0 & 0 & 0 & 0 & 0 & 1 & 0 \\
0 & 0 & 0 & 0 & 0 & 0 & 0 & 1
\end{array}\right] \quad \mathbf{R}=10^{13}\left[\begin{array}{ll}
1 & 0 \\
0 & 1
\end{array}\right] \quad \mathbf{E}=\left[\begin{array}{c}
-6.5672+0.0000 \mathrm{i} \\
-6.5672+0.0000 \mathrm{i} \\
-6.5672+0.0000 \mathrm{i} \\
-6.5672+0.0000 \mathrm{i} \\
-0.0000+0.0000 \mathrm{i} \\
-0.0000-0.0000 \mathrm{i} \\
-0.0000+0.0000 \mathrm{i} \\
-0.0000-0.0000 \mathrm{i}
\end{array}\right] \\
\mathbf{K}=\left[\begin{array}{ccccccccc}
382.1237 & -0.0000 & 39.8488 & -0.0000 & 58.1871 & -0.0001 & 6.0679 & -0.0000 \\
39.8488 & -0.0000 & 531.7027 & -0.0000 & 6.0679 & -0.0000 & 80.9639 & -0.0002
\end{array}\right] \\
\mathbf{P}=10^{17}\left[\begin{array}{ccccccccc}
0.9424 & -0.0000 & 0.0983 & -0.0000 & 0.1435 & -0.0000 & 0.0150 & -0.0000 \\
-0.0000 & 0.0000 & -0.0000 & 0.0000 & -0.0000 & 0.0000 & -0.0000 & 0.0000 \\
0.0983 & -0.0000 & 1.3113 & -0.0000 & 0.0150 & -0.0000 & 0.1997 & -0.0000 \\
-0.0000 & 0.0000 & -0.0000 & 0.0000 & -0.0000 & 0.0000 & -0.0000 & 0.0000 \\
0.1435 & -0.0000 & 0.0150 & -0.0000 & 0.0219 & -0.0000 & 0.0023 & -0.0000 \\
-0.0000 & 0.0000 & -0.0000 & 0.0000 & -0.0000 & 0.0000 & -0.0000 & 0.0000 \\
0.0150 & -0.0000 & 0.1997 & -0.0000 & 0.0023 & -0.0000 & 0.0304 & -0.0000 \\
-0.0000 & 0.0000 & -0.0000 & 0.0000 & -0.0000 & 0.0000 & -0.0000 & 0.0000
\end{array}\right]
\end{gathered}
$$

The LQR controller results and performance can be summarized as below:

- Smaller input gives a longer settling time of input and output responses.

- Minimizing the total control energy leads to maximizing the total transient energy.

- Input is directly proportional to angular velocity and settling time.

- For small angular velocities, the ball's angles' settling time is independent of angular velocity and input.

- The relationship between input and settling time, as well as input and angular velocity, cannot be deduced since many inputs can satisfy the desired system performance.

- $\theta_{x}$ has a settling time $87.14 \%$ less than its unregulated settling time while that of $\theta_{y}$ is $86.43 \%$ less than its unregulated settling time. 
- All states play role in regulating the system to the desired system performance.

Table 3. gives a numerical summary of the LQR results and performance.

Table 3. Summary of LQR results and performance.

\begin{tabular}{|c|c|c|c|c|c|c|}
\hline Response & Type & Direction & Settling Time & Maximum Value & Minimum Value & Regulation \\
\hline$T_{x}$ & Input & $x$-direction & $5.90 \mathrm{sec}$ & $30.5 \mathrm{Joule} / \mathrm{rad}$ & $-3.856 \mathrm{Joule} / \mathrm{rad}$ & Unregulated \\
\hline$T_{y}$ & Input & $y-$ direction & $6.00 \mathrm{sec}$ & $32.4 \mathrm{Joule} / \mathrm{rad}$ & $-4.097 \mathrm{Joule} / \mathrm{rad}$ & Unregulated \\
\hline$\theta_{x}$ & Output & $x-$ direction & $7.00 \mathrm{sec}$ & $0.070 \mathrm{rad}$ & $-0.01877 \mathrm{rad}$ & Unregulated \\
\hline$\theta_{y}$ & Output & $y-$ direction & $7.00 \mathrm{sec}$ & $0.070 \mathrm{rad}$ & $-0.02001 \mathrm{rad}$ & Unregulated \\
\hline$\beta_{x}$ & Output & $x-$ direction & $7.10 \mathrm{sec}$ & $0 \mathrm{rad}$ & $-1.85600 \mathrm{rad}$ & Unregulated \\
\hline$\beta_{y}$ & Output & $y-$ direction & $7.00 \mathrm{sec}$ & $0 \mathrm{rad}$ & $-1.97200 \mathrm{rad}$ & Unregulated \\
\hline$T_{x}$ & Input & $x-$ direction & $0.75 \mathrm{sec}$ & $31.0 \mathrm{Joule} / \mathrm{rad}$ & $0 \mathrm{Joule} / \mathrm{rad}$ & Regulated \\
\hline$T_{y}$ & Input & $y-$ direction & $0.70 \mathrm{sec}$ & $44.2 \mathrm{Joule} / \mathrm{rad}$ & $0 \mathrm{Joule} / \mathrm{rad}$ & Regulated \\
\hline$\theta_{x}$ & Output & $x-$ direction & $0.90 \mathrm{sec}$ & $0.070 \mathrm{rad}$ & $0 \mathrm{rad}$ & Regulated \\
\hline$\theta_{y}$ & Output & $y-$ direction & $0.95 \mathrm{sec}$ & $0.070 \mathrm{rad}$ & $0 \mathrm{rad}$ & Regulated \\
\hline
\end{tabular}

\section{LQG}

Using the same desired initial conditions in Table 2., for the LQG unregulated control of the system, the inputs to the system are $58.5 \mathrm{Joule} / \mathrm{rad}$ and $58.4 \mathrm{Joule} / \mathrm{rad}$ maximum and $-13.90 \mathrm{Joule} / \mathrm{rad}$ and $-14.80 \mathrm{Joule} / \mathrm{rad}$ minimum in the $x$ and $y$ directions, respectively, while the settling time in the $x$-direction is $6.65 \mathrm{sec}$ and $6.70 \mathrm{sec}$ in the $y$-direction. It can be noticed that the settling time and maximum input (torque) are almost the same for both directions even though the angular velocities are different. It was observed that for small angular velocities, settling time and maximum input value are independent of angular velocity. Comparing the unregulated values with that of unregulated LQR, it can be noticed that the unregulated LQG inputs' values are higher even though the same initial conditions are applied to both controllers. This was found out to be because the LQG controller has a combination of Kalman gain and LQR feedback gain. The input responses are shown in Fig. 18. and Fig. 19. for $x$ and $y$ directions, respectively.

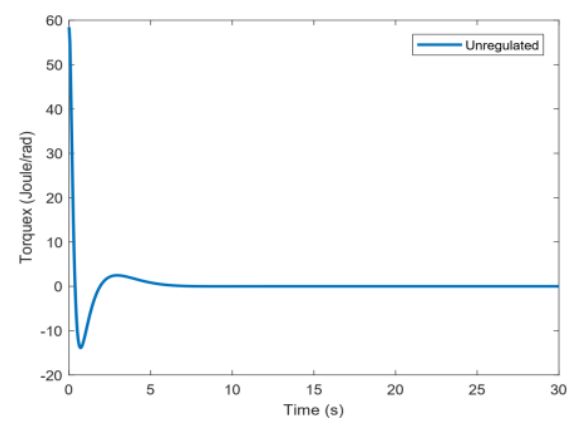

Fig. 18. LQG unregulated input response in the $x$ - direction, $T_{x}$.

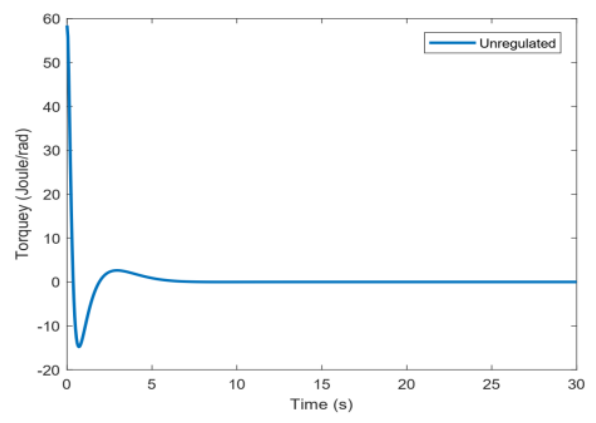

Fig. 19. LQG unregulated input response in the $y$ - direction, $T_{y}$.

From Fig. 20. and Fig. 21., the settling time is $6.80 \mathrm{sec}$ for the ball's angle with respect to the $x$ - direction while it is $6.75 \mathrm{sec}$ with respect to the $y$ - direction. With different angular velocities, it can be noticed that the settling time is almost the same for both directions. This is also the case with the unregulated LQR responses. But comparing the settling time with that of unregulated LQR output responses (Fig. 8. and Fig. 9.), it can be observed that the LQR controller settles slower than the LQG controller. 


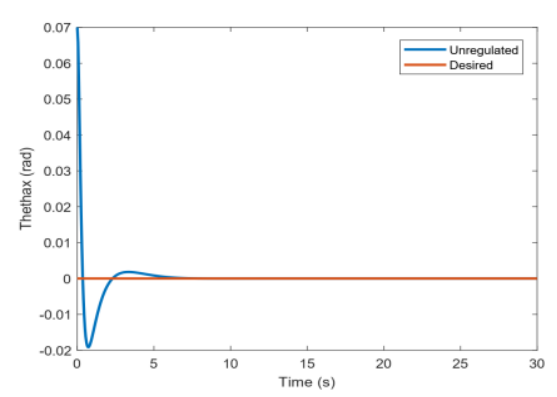

Fig. 20. LQG unregulated output response in the $x$ - direction, $\theta_{x}$.

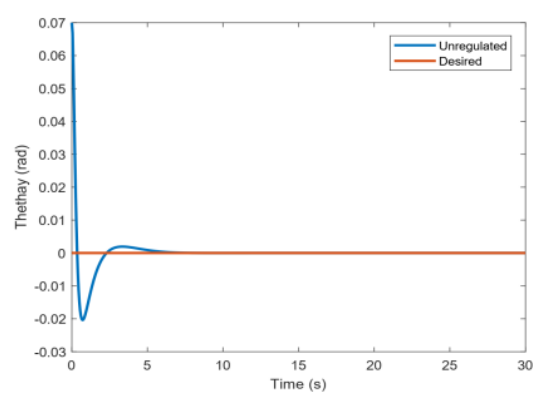

Fig. 21. LQG unregulated output response in the $y$ - direction, $\theta_{y}$.

The sphere's angle response settles faster in the $y$-direction than in the $x$-direction with 6.90 sec settling time in the $y$ - direction and $7.10 \mathrm{sec}$ in the $x$-direction, Fig. 22. and Fig. 23., even though angular velocity is higher in the $y$-direction. This shows that settling time and angular velocity are inversely proportional to the sphere's angle. On comparing the sphere's angle unregulated responses with that of unregulated LQR responses (Fig. 10. and Fig. 11.), it can be noticed that they are the same in $x$-direction but different in $y$-direction. The sphere's angle, like that of LQR, also settles faster in the $y$ - direction for the unregulated LQG response.

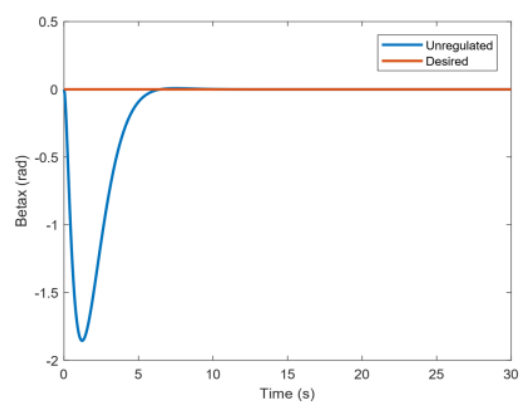

Fig. 22. LQG unregulated output response in the $x$-direction, $\beta_{x}$.

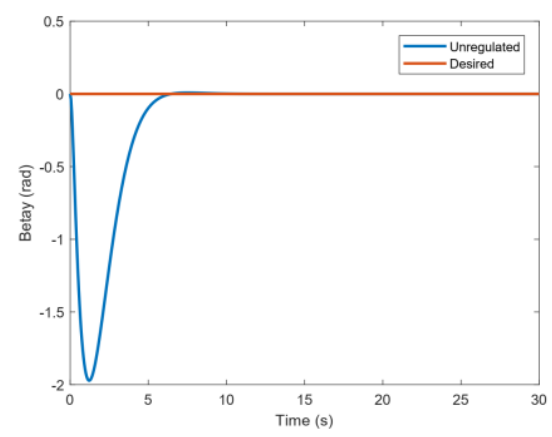

Fig. 23. LQG unregulated output response in the $y-$ direction, $\beta_{y}$.

The matrices that give these unregulated responses in Fig. 18. through Fig. 23. are as below. 


$$
\begin{aligned}
& \mathbf{Q}=\left[\begin{array}{llllllll}
1 & 0 & 0 & 0 & 0 & 0 & 0 & 0 \\
0 & 1 & 0 & 0 & 0 & 0 & 0 & 0 \\
0 & 0 & 1 & 0 & 0 & 0 & 0 & 0 \\
0 & 0 & 0 & 1 & 0 & 0 & 0 & 0 \\
0 & 0 & 0 & 0 & 1 & 0 & 0 & 0 \\
0 & 0 & 0 & 0 & 0 & 1 & 0 & 0 \\
0 & 0 & 0 & 0 & 0 & 0 & 1 & 0 \\
0 & 0 & 0 & 0 & 0 & 0 & 0 & 1
\end{array}\right] \quad \mathbf{R}=\left[\begin{array}{ll}
1 & 0 \\
0 & 1
\end{array}\right] \quad \mathbf{E}=\left[\begin{array}{l}
-6.7017+0.0000 \mathrm{i} \\
-6.7017+0.0000 \mathrm{i} \\
-6.4354+0.0000 \mathrm{i} \\
-6.4354+0.0000 \mathrm{i} \\
-0.8715+0.0000 \mathrm{i} \\
-0.8715-0.0000 \mathrm{i} \\
-0.8715+0.0000 \mathrm{i} \\
-0.8715-0.0000 \mathrm{i}
\end{array}\right] \\
& \mathbf{K}=\left[\begin{array}{cccccccc}
417.4791 & -1.0000 & -0.0000 & 0.0000 & 63.5795 & -2.0312 & -0.0000 & 0.0000 \\
-0.0000 & 0.0000 & 417.4791 & -1.0000 & -0.0000 & 0.0000 & 63.5795 & -2.0312
\end{array}\right] \\
& \mathbf{P}=10^{4}\left[\begin{array}{cccccccc}
1.3272 & -0.0064 & -0.0000 & 0.0000 & 0.2021 & -0.0119 & -0.0000 & 0.0000 \\
-0.0064 & 0.0002 & 0.0000 & -0.0000 & -0.0010 & 0.0002 & 0.0000 & -0.0000 \\
-0.0000 & 0.0000 & 1.3272 & -0.0064 & -0.0000 & 0.0000 & 0.2021 & -0.0119 \\
0.0000 & -0.0000 & -0.0064 & 0.0002 & 0.0000 & -0.0000 & -0.0010 & 0.0002 \\
0.2021 & -0.0010 & -0.0000 & 0.0000 & 0.0308 & -0.0018 & -0.0000 & 0.0000 \\
-0.0119 & 0.0002 & 0.0000 & -0.0000 & -0.0018 & 0.0003 & 0.0000 & -0.0000 \\
-0.0000 & 0.0000 & 0.2021 & -0.0010 & -0.0000 & 0.0000 & 0.0308 & -0.0018 \\
0.0000 & -0.0000 & -0.0119 & 0.0002 & 0.0000 & -0.0000 & -0.0018 & 0.0003
\end{array}\right] \\
& \mathbf{A}(T)=10^{3}\left[\begin{array}{cccccccc}
0.3557 & 0 & 0 & 0 & 0.0542 & 0 & 0 & 0 \\
0.0002 & 0.0010 & 0 & 0 & 0.0000 & 0.0010 & 0 & 0 \\
0 & 0 & 0.3557 & 0 & 0 & 0 & 0.0542 & 0 \\
0 & 0 & 0.0002 & 0.0010 & 0 & 0 & 0.0000 & 0.0010 \\
2.3358 & 0 & 0 & 0 & 0.3557 & 0 & 0 & 0 \\
0.0014 & 0 & 0 & 0 & 0.0002 & 0.0010 & 0 & 0 \\
0 & 0 & 2.3358 & 0 & 0 & 0 & 0.3557 & 0 \\
0 & 0 & 0.0014 & 0 & 0 & 0 & 0.0002 & 0.0010
\end{array}\right] \\
& \mathbf{B}(T)=\left[\begin{array}{cc}
2.1900 & 0 \\
0.5061 & 0 \\
0 & 2.1900 \\
0 & 0.5061 \\
14.4224 & 0 \\
1.0181 & 0 \\
0 & 14.4224 \\
0 & 1.0181
\end{array}\right] \quad \mathbf{C}_{\mathrm{d}}=\left[\begin{array}{cccccccc}
1 & 0 & 0 & 0 & 0 & 0 & 0 & 0 \\
0 & 1 & 0 & 0 & 0 & 0 & 0 & 0 \\
0 & 0 & 1 & 0 & 0 & 0 & 0 & 0 \\
0 & 0 & 0 & 1 & 0 & 0 & 0 & 0 \\
0 & 0 & 0 & 0 & 1 & 0 & 0 & 0 \\
0 & 0 & 0 & 0 & 0 & 1 & 0 & 0 \\
0 & 0 & 0 & 0 & 0 & 0 & 1 & 0 \\
0 & 0 & 0 & 0 & 0 & 0 & 0 & 1
\end{array}\right] \quad \mathbf{R}_{\mathrm{e}}=\left[\begin{array}{cccc}
1 & 0 & 0 & 0 \\
0 & 1 & 0 & 0 \\
0 & 0 & 1 & 0 \\
0 & 0 & 0 & 1
\end{array}\right] \\
& \mathbf{Q}_{\mathrm{e}}=\left[\begin{array}{llllllll}
1 & 0 & 0 & 0 & 0 & 0 & 0 & 0 \\
0 & 1 & 0 & 0 & 0 & 0 & 0 & 0 \\
0 & 0 & 1 & 0 & 0 & 0 & 0 & 0 \\
0 & 0 & 0 & 1 & 0 & 0 & 0 & 0 \\
0 & 0 & 0 & 0 & 1 & 0 & 0 & 0 \\
0 & 0 & 0 & 0 & 0 & 1 & 0 & 0 \\
0 & 0 & 0 & 0 & 0 & 0 & 1 & 0 \\
0 & 0 & 0 & 0 & 0 & 0 & 0 & 1
\end{array}\right] \quad \mathbf{L}=\left[\begin{array}{ccccc}
1.0000 & 0.0001 & 0 & 0 \\
0.0001 & 0.7647 & 0 & 0 \\
0 & 0 & 1.0000 & 0.0001 \\
0 & 0 & 0.0001 & 0.7647 \\
6.5667 & 0.0010 & 0 & 0 \\
0.0037 & 0.3529 & 0 & 0 \\
0 & 0 & 6.5667 & 0.0010 \\
0 & 0 & 0.0037 & 0.3529
\end{array}\right] \\
& \mathbf{P}_{3}=\left[\begin{array}{cccccccc}
1.0000 & 0.0001 & 0 & 0 & 6.5667 & 0.0037 & 0 & 0 \\
0.0001 & 0.7647 & 0 & 0 & 0.0010 & 0.3529 & 0 & 0 \\
0 & 0 & 1.0000 & 0.0001 & 0 & 0 & 6.5667 & 0.0037 \\
0 & 0 & 0.0001 & 0.7647 & 0 & 0 & 0.0010 & 0.3529 \\
6.5667 & 0.0010 & 0 & 0 & 44.1184 & 0.0244 & 0 & 0 \\
0.0037 & 0.3529 & 0 & 0 & 0.0244 & 1.4706 & 0 & 0 \\
0 & 0 & 6.5667 & 0.0010 & 0 & 0 & 44.1184 & 0.0244 \\
0 & 0 & 0.0037 & 0.3529 & 0 & 0 & 0.0244 & 1.4706
\end{array}\right]
\end{aligned}
$$

Here $\mathbf{A}(T)$ is the discrete-time transition matrix, $\mathbf{B}(T)$ is the discrete-time control matrix, $\mathbf{C}_{\mathrm{d}}$ is the disturbance matrix, $\mathbf{R}_{\mathrm{e}}$ is the measurement noise covariance matrix, $\mathbf{Q}_{\mathrm{e}}$ is the disturbance noise covariance matrix, $\mathbf{L}$ is the Kalman gain matrix, and $\mathbf{P}_{3}$ is the estimation error covariance matrix after 0 iterations.

Regulating the system/controller matrices to get the desired system performance, two of the many inputs that meet the desired performance are found to have $48.1 \mathrm{Joule} / \mathrm{rad}$ and $50.0 \mathrm{Joule} / \mathrm{rad}$ in $x$ and $y$ directions, respectively, with a settling time of $1.20 \mathrm{sec}$ for input in the $x$ - direction and $1.10 \mathrm{sec}$ for input in the $y-$ direction. These responses are shown in Fig. 24. and Fig. 25. When these values are compared with that of regulated LQR input responses, it can be observed that the regulated LQG has higher input values and settling times. This means that the regulated LQG input 
responses settle slower than regulated LQR input responses. For the regulated LQG also the relationship between input and settling time, as well as input and angular velocity, cannot be deduced since many inputs can satisfy the desired system performance.

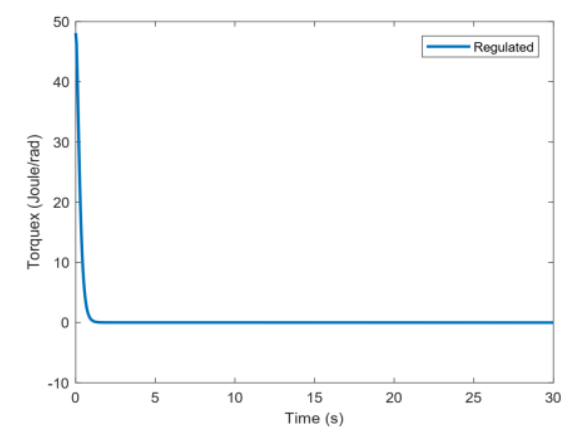

Fig. 24. LQG regulated input response in the $x$ - direction, $T_{x}$.

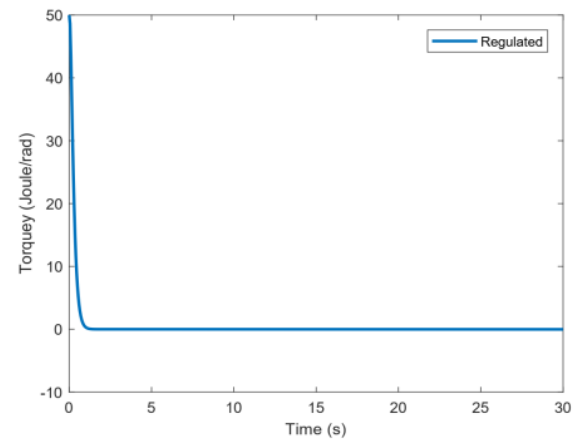

Fig. 25. LQG regulated input response in the $y-$ direction, $T_{y}$.

For the regulated system, the output responses have a settling time of $1.20 \mathrm{sec}$ and $1.15 \mathrm{sec}$ for the ball's angle with respect to $x$ and $y$ directions, respectively. The $1.20 \mathrm{sec}$ settling time of $\theta_{x}$ is $17.65 \%$ of its unregulated settling time (Fig. 20.) which is $6.80 \mathrm{sec}$. This means that $\theta_{x}$ has a settling time $82.35 \%$ less than its unregulated settling time. While $\theta_{y}$ has a settling time $82.96 \%$ less than its unregulated settling time. On comparing these values with that of regulated LQR responses, it can be observed that LQR responses settle faster than LQG responses. Efforts were made to get a settling time of less than $1.00 \mathrm{sec}$ for the regulated LQG but unfortunately, such value could not be realized. This shows that LQR is more efficient with regulation. The responses are shown in Fig. 26. and Fig. 27.

Fig. 28. and Fig. 29. show the regulated output responses $\beta_{x}$ and $\beta_{y}$.

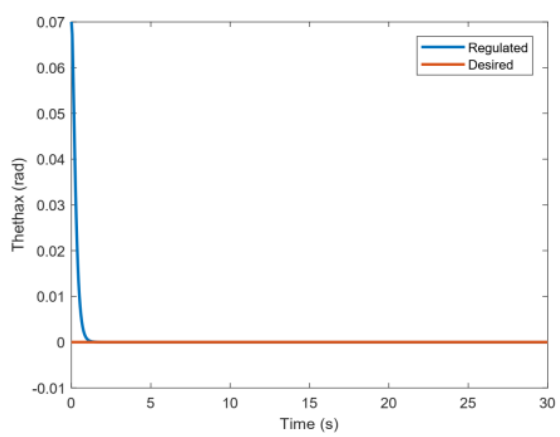

Fig. 26. LQG regulated output response in the $x$ - direction, $\theta_{x}$. 


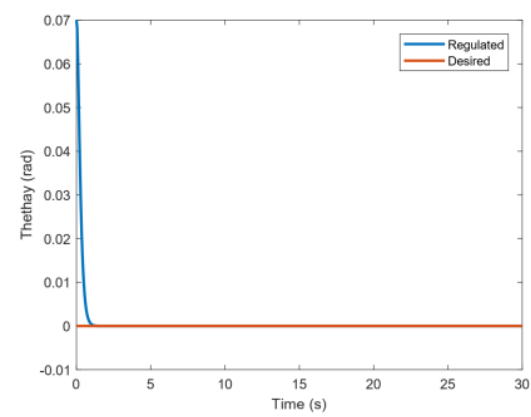

Fig. 27. LQG regulated output response in the $y-$ direction, $\theta_{y}$.

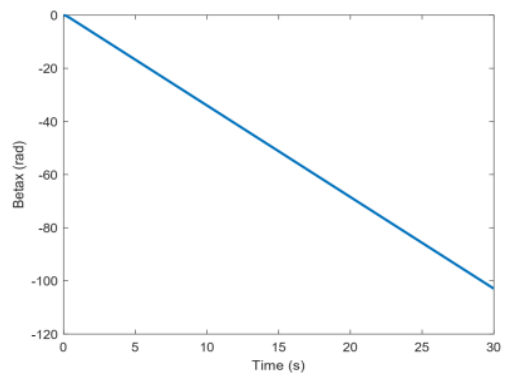

Fig. 28. LQG regulated output response in the $x$ - direction, $\beta_{x}$.

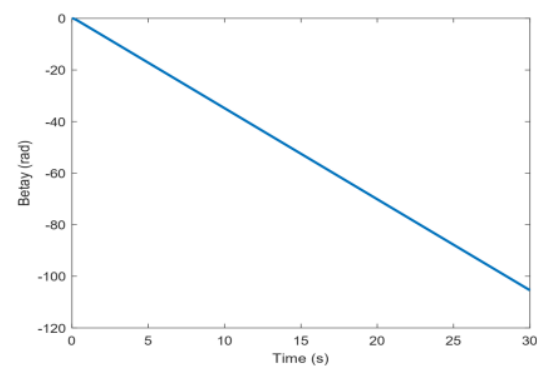

Fig. 29. LQG regulated output response in the $y-$ direction, $\beta_{y}$.

The regulated system matrices are as below.

It is also observed that all states play role in regulating the system to desired system performance.

$$
\begin{gathered}
\mathbf{Q}=10^{-7}\left[\begin{array}{cccccccc}
1 & 0 & 0 & 0 & 0 & 0 & 0 & 0 \\
0 & 1 & 0 & 0 & 0 & 0 & 0 & 0 \\
0 & 0 & 1 & 0 & 0 & 0 & 0 & 0 \\
0 & 0 & 0 & 1 & 0 & 0 & 0 & 0 \\
0 & 0 & 0 & 0 & 1 & 0 & 0 & 0 \\
0 & 0 & 0 & 0 & 0 & 1 & 0 & 0 \\
0 & 0 & 0 & 0 & 0 & 0 & 1 & 0 \\
0 & 0 & 0 & 0 & 0 & 0 & 0 & 1
\end{array}\right] \quad \mathbf{R}=10^{13}\left[\begin{array}{cc}
1 & 0 \\
0 & 1
\end{array}\right] \quad \mathbf{E}=\left[\begin{array}{c}
-6.5672+0.0000 \mathrm{i} \\
-6.5672+0.0000 \mathrm{i} \\
-6.5672+0.0000 \mathrm{i} \\
-6.5672+0.0000 \mathrm{i} \\
-0.0000+0.0000 \mathrm{i} \\
-0.0000-0.0000 \mathrm{i} \\
-0.0000+0.0000 \mathrm{i} \\
-0.0000-0.0000 \mathrm{i}
\end{array}\right] \\
\mathbf{K}=\left[\begin{array}{ccccccccc}
300.8385 & -0.0000 & 42.7703 & -0.0000 & 45.8095 & -0.0000 & 6.5128 & -0.0000 \\
42.7703 & -0.0000 & 314.3527 & -0.0000 & 6.5127 & -0.0000 & 47.8674 & -0.0000
\end{array}\right] \\
\mathbf{P}=10^{16}\left[\begin{array}{ccccccccc}
7.4190 & -0.0000 & 1.0548 & -0.0000 & 1.1297 & -0.0000 & 0.1606 & -0.0000 \\
-0.0000 & 0.0000 & -0.0000 & -0.0000 & -0.0000 & 0.0000 & -0.0000 & -0.0000 \\
1.0548 & -0.0000 & 7.7523 & -0.0000 & 0.1606 & -0.0000 & 1.1805 & -0.0000 \\
-0.0000 & -0.0000 & -0.0000 & 0.0000 & -0.0000 & -0.0000 & -0.0000 & 0.0000 \\
1.1297 & -0.0000 & 0.1606 & -0.0000 & 0.1720 & -0.0000 & 0.0245 & -0.0000 \\
-0.0000 & 0.0000 & -0.0000 & -0.0000 & -0.0000 & 0.0000 & -0.0000 & -0.0000 \\
0.1606 & -0.0000 & 1.1805 & -0.0000 & 0.0245 & -0.0000 & 0.1798 & -0.0000 \\
-0.0000 & -0.0000 & -0.0000 & 0.0000 & -0.0000 & -0.0000 & -0.0000 & 0.0000
\end{array}\right]
\end{gathered}
$$




$$
\begin{aligned}
& \mathbf{A}(T)=10^{3}\left[\begin{array}{cccccccc}
0.3557 & 0 & 0 & 0 & 0.0542 & 0 & 0 & 0 \\
0.0002 & 0.0010 & 0 & 0 & 0.0000 & 0.0010 & 0 & 0 \\
0 & 0 & 0.3557 & 0 & 0 & 0 & 0.0542 & 0 \\
0 & 0 & 0.0002 & 0.0010 & 0 & 0 & 0.0000 & 0.0010 \\
2.3358 & 0 & 0 & 0 & 0.3557 & 0 & 0 & 0 \\
0.0014 & 0 & 0 & 0 & 0.0002 & 0.0010 & 0 & 0 \\
0 & 0 & 2.3358 & 0 & 0 & 0 & 0.3557 & 0 \\
0 & 0 & 0.0014 & 0 & 0 & 0 & 0.0002 & 0.0010
\end{array}\right] \\
& \mathbf{B}(T)=\left[\begin{array}{cc}
2.1900 & 0 \\
0.5061 & 0 \\
0 & 2.1900 \\
0 & 0.5061 \\
14.4224 & 0 \\
1.0181 & 0 \\
0 & 14.4224 \\
0 & 1.0181
\end{array}\right] \quad \mathbf{C}_{\mathrm{d}}=\left[\begin{array}{cccccccc}
0.1 & 0 & 0 & 0 & 0 & 0 & 0 & 0 \\
0 & 0.1 & 0 & 0 & 0 & 0 & 0 & 0 \\
0 & 0 & 0.1 & 0 & 0 & 0 & 0 & 0 \\
0 & 0 & 0 & 0.1 & 0 & 0 & 0 & 0 \\
0 & 0 & 0 & 0 & 0.1 & 0 & 0 & 0 \\
0 & 0 & 0 & 0 & 0 & 0.1 & 0 & 0 \\
0 & 0 & 0 & 0 & 0 & 0 & 0.1 & 0 \\
0 & 0 & 0 & 0 & 0 & 0 & 0 & 0.1
\end{array}\right] \\
& \mathbf{R}_{\mathrm{e}}=10^{-3}\left[\begin{array}{cccc}
1 & 0 & 0 & 0 \\
0 & 1 & 0 & 0 \\
0 & 0 & 1 & 0 \\
0 & 0 & 0 & 1
\end{array}\right] \quad \mathbf{Q}_{\mathrm{e}}=\left[\begin{array}{cccccccc}
0.1 & 0 & 0 & 0 & 0 & 0 & 0 & 0 \\
0 & 0.1 & 0 & 0 & 0 & 0 & 0 & 0 \\
0 & 0 & 0.1 & 0 & 0 & 0 & 0 & 0 \\
0 & 0 & 0 & 0.1 & 0 & 0 & 0 & 0 \\
0 & 0 & 0 & 0 & 0.1 & 0 & 0 & 0 \\
0 & 0 & 0 & 0 & 0 & 0.1 & 0 & 0 \\
0 & 0 & 0 & 0 & 0 & 0 & 0.1 & 0 \\
0 & 0 & 0 & 0 & 0 & 0 & 0 & 0.1
\end{array}\right] \\
& \mathbf{L}=\left[\begin{array}{cccc}
1.0000 & 0.0000 & 0 & 0 \\
0.0000 & 0.9995 & 0 & 0 \\
0 & 0 & 1.0000 & 0.0000 \\
0 & 0 & 0.0000 & 0.9995 \\
6.5671 & 0.0000 & 0 & 0 \\
0.0036 & 0.4997 & 0 & 0 \\
0 & 0 & 6.5671 & 0.0000 \\
0 & 0 & 0.0036 & 0.4997
\end{array}\right] \\
& \mathbf{P}_{3}=\left[\begin{array}{cccccccc}
0.0010 & 0.0000 & 0 & 0 & 0.0066 & 0.0000 & 0 & 0 \\
0.0000 & 0.0010 & 0 & 0 & 0.0000 & 0.0005 & 0 & 0 \\
0 & 0 & 0.0010 & 0.0000 & 0 & 0 & 0.0066 & 0.0000 \\
0 & 0 & 0.0000 & 0.0010 & 0 & 0 & 0.0000 & 0.0005 \\
0.0066 & 0.0000 & 0 & 0 & 0.0442 & 0.0000 & 0 & 0 \\
0.0000 & 0.0005 & 0 & 0 & 0.0000 & 0.5011 & 0 & 0 \\
0 & 0 & 0.0066 & 0.0000 & 0 & 0 & 0.0442 & 0.0000 \\
0 & 0 & 0.0000 & 0.0005 & 0 & 0 & 0.0000 & 0.5011
\end{array}\right]
\end{aligned}
$$

The LQG controller results and performance can be summarized as below:

- Larger input gives a longer settling time of input and output responses.

- Minimizing the total control energy leads to maximizing the total transient energy.

- Input is independent of angular velocity and settling time.

- For small angular velocities, the ball's angles' settling time is independent of angular velocity and input.

- Settling time and angular velocity are inversely proportional to the sphere's angle.

- The relationship between input and settling time, as well as input and angular velocity, cannot be deduced since many inputs can satisfy the desired system performance.

- $\quad \theta_{x}$ has a settling time $82.35 \%$ less than its unregulated settling time while that of $\theta_{y}$ is $82.96 \%$ less than its unregulated settling time.

- All states play role in regulating the system to the desired system performance.

- Recursive iterations lead (not generally) to unstable input.

Table 4. gives a numerical summary of the LQG results and performance. 
Table 4. Summary of LQG results and performance.

\begin{tabular}{|c|c|c|c|c|c|c|}
\hline Response & Type & Direction & Settling Time & Maximum Value & Minimum Value & Regulation \\
\hline$T_{x}$ & Input & $x-$ direction & $6.65 \mathrm{sec}$ & $58.5 \mathrm{Joule} / \mathrm{rad}$ & $-13.90 \mathrm{Joule} / \mathrm{rad}$ & Unregulated \\
\hline$T_{y}$ & Input & $y$-direction & $6.70 \mathrm{sec}$ & $58.4 \mathrm{Joul} / \mathrm{rad}$ & $-14.80 \mathrm{Joule} / \mathrm{rad}$ & Unregulated \\
\hline$\theta_{x}$ & Output & $x-$ direction & $6.80 \mathrm{sec}$ & $0.070 \mathrm{rad}$ & $-0.01908 \mathrm{rad}$ & Unregulated \\
\hline$\theta_{y}$ & Output & $y-$ direction & $6.75 \mathrm{sec}$ & $0.070 \mathrm{rad}$ & $-0.02031 \mathrm{rad}$ & Unregulated \\
\hline$\beta_{x}$ & Output & $x-$ direction & $7.10 \mathrm{sec}$ & $0 \mathrm{rad}$ & $-1.85600 \mathrm{rad}$ & Unregulated \\
\hline$\beta_{y}$ & Output & $y-$ direction & $6.90 \mathrm{sec}$ & $0 \mathrm{rad}$ & $-1.97200 \mathrm{rad}$ & Unregulated \\
\hline$T_{x}$ & Input & $x-$ direction & $1.20 \mathrm{sec}$ & $48.1 \mathrm{Joule} / \mathrm{rad}$ & $0 \mathrm{Joule} / \mathrm{rad}$ & Regulated \\
\hline$T_{y}$ & Input & $y-$ direction & $1.10 \mathrm{sec}$ & $50.0 \mathrm{Joule} / \mathrm{rad}$ & $0 \mathrm{Joule} / \mathrm{rad}$ & Regulated \\
\hline$\theta_{x}$ & Output & $x-$ direction & $1.20 \mathrm{sec}$ & $0.070 \mathrm{rad}$ & $0 \mathrm{rad}$ & Regulated \\
\hline$\theta_{y}$ & Output & $y-$ direction & $1.15 \mathrm{sec}$ & $0.070 \mathrm{rad}$ & $0 \mathrm{rad}$ & Regulated \\
\hline
\end{tabular}

\section{Comparative Analysis of LQR and LQG}

A comparison of the two controllers, based on their general performance and desired performance, is given in Table 5.

Table 5. Comparison of LQR and LQG

\begin{tabular}{|c|c|c|}
\hline & LQR & LQG \\
\hline Inputs $\left(T_{x}\right.$ and $\left.T_{y}\right)$ & $\begin{array}{l}\text { The smaller the input the longer the settling } \\
\text { time of input and output responses }\end{array}$ & $\begin{array}{l}\text { The larger the input the longer the settling time of input and } \\
\text { output responses }\end{array}$ \\
\hline Energy ( $\mathbf{Q}$ and $\mathbf{R}$ matrices) & $\begin{array}{l}\text { Minimizing the total control energy leads to } \\
\text { maximizing the total transient energy }\end{array}$ & $\begin{array}{l}\text { Minimizing the total control energy leads to maximizing the } \\
\text { total transient energy but LQG maximizes the total transient } \\
\text { energy more than LQR }\end{array}$ \\
\hline $\begin{array}{l}\text { Angular Velocity/Settling } \\
\text { Time } \\
\end{array}$ & $\begin{array}{l}\text { Angular velocity and settling time are } \\
\text { directly proportional to the input }\end{array}$ & Angular velocity and settling time are independent of the input \\
\hline Ball's Angles $\left(\theta_{x}\right.$ and $\left.\theta_{y}\right)$ & $\begin{array}{l}\text { The settling time of the ball's angles is } \\
\text { independent of angular velocity and input }\end{array}$ & $\begin{array}{l}\text { The settling time of the ball's angles is independent of angular } \\
\text { velocity and input }\end{array}$ \\
\hline $\begin{array}{l}\text { Ball's Angles }\left(\theta_{x} \text { and } \theta_{y}\right) \\
\text { Performance }\end{array}$ & $\begin{array}{l}\text { With } \theta_{x} \text { is } 87.14 \% \text { and } \theta_{y} \text { is } 86.43 \% \text { less } \\
\text { than their respective unregulated settling } \\
\text { times, LQR satisfies the at least } 80 \% \\
\text { performance requirement more than LQG }\end{array}$ & $\begin{array}{l}\text { For LQG, } \theta_{x} \text { is } 82.35 \% \text { and } \theta_{y} \text { is } 82.95 \% \text { less than their } \\
\text { respective unregulated settling times. These values are less than } \\
\text { that of LQR }\end{array}$ \\
\hline States & $\begin{array}{l}\text { All states play role in regulating the } \\
\text { system/controller to the desired system } \\
\text { performance }\end{array}$ & $\begin{array}{l}\text { All states play role in regulating the system/controller to the } \\
\text { desired system performance }\end{array}$ \\
\hline Gain & LQR gain is computed in reverse-time & Kalman filter gain is computed in forward-time \\
\hline Gain & LQR has a state feedback gain matrix & $\begin{array}{l}\text { LQG has LQR's state feedback gain matrix and Kalman filter } \\
\text { gain matrix }\end{array}$ \\
\hline Overshoot & Zero overshoot could be & Zero overshoot could be achieved \\
\hline Overall Performance & LQR is more efficient than LQG & $\begin{array}{l}\text { Because in LQG, settling time (of ball's angles) of less than } \\
1.00 \text { sec could not be realized }\end{array}$ \\
\hline
\end{tabular}

Table 5. gives a comprehensive comparative analysis of the two controllers' performances, which is the main aim of the research. One of the research goals is to find $\mathbf{Q}$ and $\mathbf{R}$ matrices, this goal is achieved and matrices' performance in terms of energy is analyzed in the table. Another goal is to do a performance analysis of the two controllers comparatively, and this is given in Table 5.

\section{Conclusion}

LQR and LQG are controllers that are gaining popularity among the optimal controllers currently available but unfortunately, they are rarely covered in the literature for an important system like ball-on-sphere. So, the main aim of this research work was to do a comparative analysis of LQR and LQG for the ball-on-sphere system.

This aim was achieved by executing the goals as follows: first investigating the system's dynamics and deriving the mathematical model of the system using the Lagrangian method by considering some assumptions. Then, the system was linearized (due to its nonlinear nature) and a state-space representation of the system was derived. Using the statespace model of the system, optimal LQR and LQG controllers were then designed and implemented using MATLAB, first without regulation, and then the controllers were regulated (through manipulation of matrices by trial and error method) to get the desired system performance. Finally, controllers' performances were analyzed and compared.

Without regulation, the LQG controller was observed to give a better performance in terms of the settling time of the output responses but longer settling time of the inputs.

But with regulation, based on the desired system performance, LQR was found to be more efficient in terms of both input and output responses' settling time. 
Another important finding was that LQG could not be regulated for the output (ball's angles) responses to have a settling time of less than $1.00 \mathrm{sec}$.

Also, both controllers were able to satisfy the desired system performance requirement set by the research work. But on comparing the performances, LQR satisfied more than LQG.

Another finding was that even though both controllers minimize the total control energy (while maximizing the total transient energy), LQG maximizes the total transient energy more than LQR.

With this research, the identified gap in the literature has been bridged and future work can use this research as a basis.

\section{References}

[1] N. S. Nise, CONTROL SYSTEMS ENGINEERING, 6th Edition. California State Polytechnic University, Pomona: John Wiley \& Sons, Inc., 2011.

[2] B. Xu, 'A Comparative Study of PID and LQR Control Strategies Applied to Inverted Pendulum Systems', Master of Engineering, M.Eng, University of Guelph, Ontario, Canada, 2019.

[3] E. Zakeri, S. A. Moezi, and Y. Bazargan-Lari, 'Control of a Ball on Sphere System with Adaptive Feedback Linearization method for regulation purpose', Majlesi J. Mechatron. Eng., vol. 2, no. 3, pp. 23-27, Sep. 2013.

[4] Y.-H. Chang, W.-S. Chan, and C.-W. Chang, 'T-S Fuzzy Model-Based Adaptive Dynamic Surface Control for Ball and Beam System', IEEE Trans. Ind. Electron., vol. 60, no. 6, pp. 2251-2263, Jun. 2013, doi: 10.1109/TIE.2012.2192891.

[5] M.-T. Ho, Y.-W. Tu, and H.-S. Lin, 'Controlling a ball and wheel system using full-state-feedback linearization [Focus on Education]', IEEE Control Syst., vol. 29, no. 5, pp. 93-101, Oct. 2009, doi: 10.1109/MCS.2009.934085.

[6] A. Buschhaus and S. Schmal, 'Robolab Reutlingen University', https://vvl.reutlingen-university.de/homepage/en/index.html. https://vvl.reutlingen-university.de/homepage/en/index.html\#demos/ballOnBall/main (accessed Aug. 26, 2020).

[7] A. D. Usman, A. M. Yusuf, A. Umar, and A. Daniel, 'Structual analysis of ball-on-sphere system using bond graph technique', in 2017 IEEE 3rd International Conference on Electro-Technology for National Development (NIGERCON), Owerri, Nov. 2017, pp. 519-524, doi: 10.1109/NIGERCON.2017.8281921.

[8] M.-T. Ho, Y. Rizal, and W.-S. Cheng, 'Stabilization of a Vision-Based Ball-On-Sphere System', in 2013 IEEE International Conference on Control Applications (CCA), Part of 2013 IEEE Multi-Conference on Systems and Control, Hyderabad, India, Aug. 2013, pp. 929-934, doi: 10.1109/CCA.2013.6662870.

[9] A. Umar, Z. Haruna, U. Musa, S. A. Mohammed, and M. O. Muyideen, 'Graphical User Interface (GUI) for Position and Trajectory Tracking Control of the Ball and Plate System Using H-Infinity Controller', doi: 10.20370/YHAS-N460.

[10] M. Rahman, S. K. Sarkar, S. K. Das, and Y. Miao, 'A comparative study of LQR, LQG, and integral LQG controller for frequency control of interconnected smart grid', in 2017 3rd International Conference on Electrical Information and Communication Technology (EICT), Khulna, Dec. 2017, pp. 1-6, doi: 10.1109/EICT.2017.8275216.

[11] A. H. O. Ahmed, M. O. Ajangnay, and M. W. Dunnigan, 'New Approach for Position Control of Induction Motor', in 45th International Universities Power Engineering Conference UPEC2010, Cardiff, Wales, UK, Sep. 2010, pp. 1-5.

[12] D. S. Naidu, Optimal control systems. Boca Raton, Fla: CRC Press, 2003.

[13] V. Kumar and J. Jerome, 'Robust LQR Controller Design for Stabilizing and Trajectory Tracking of Inverted Pendulum', Procedia Eng., vol. 64, pp. 169-178, 2013, doi: 10.1016/j.proeng.2013.09.088.

[14] H. Jafari, A. Rahimpour, and M. Pourrahim, 'Linear Quadratic Gaussian Control for ball and plate system', in 2012 international conference on computer, control, education and management, Dubai, United Arab Emirates, Jul. 2012, pp. 1-7.

[15] W. Favoreell and B. D. Moor, 'Model-free subspace-based LQG-design', in Proceedings of the American Control Conference (ACC), San Diego, California, Jun. 1999, pp. 3372-3376, doi: 10.1109/ACC.1999.782390.

[16] R. Szabolcsi, 'DESIGN AND DEVELOPMENT OF THE LQR OPTIMAL CONTROLLER FOR THE UNMANNED AERIAL VEHICLE', Rev. Air Force Acad., vol. 16, no. 1, pp. 45-54, Aug. 2018, doi: 10.19062/1842-9238.2018.16.1.7.

[17] A. Toloei, E. Aghamirbaha, and M. Zarchi, 'Mathematical Model and Vibration Analysis of Aircraft with Active Landing Gear System using Linear Quadratic Regulator Technique', Int. J. Eng., vol. 29, no. 2, Feb. 2016, doi: 10.5829/idosi.ije.2016.29.02b.01.

[18] S.-Y. Liu, Y. Rizal, and M.-T. Ho, 'Stabilization of a Ball and Sphere System Using Feedback Linearization and Sliding Mode Control', in 2011 8th Asian Control Conference (ASCC), Kaohsiung, Taiwan, May 2011, pp. 1334-1339.

[19] U. Mohammed, U. H. Suleiman, M. Usman, and T. Sadiq, 'Design of an Optimal Linear Quadratic Regulator (LQR) Controller for the Ball-On-Sphere System', Int. J. Eng. Manuf., vol. 10, no. 3, pp. 56-70, Jun. 2020, doi: 10.5815/ijem.2020.03.05.

[20] K. Anurag and S. Kamlu, 'Design of LQR-PID controller for linearized magnetic levitation system', in 2018 2nd International Conference on Inventive Systems and Control (ICISC), Coimbatore, Jan. 2018, pp. 444-447, doi: 10.1109/ICISC.2018.8399112.

[21] A. Ashraf, W. Mei, L. Gaoyuan, Z. Anjum, and M. M. Kamal, 'Design Linear Feedback and LQR Controller for Lateral Flight Dynamics of F-16 Aircraft', in 2018 International Conference on Control, Automation and Information Sciences (ICCAIS), Hangzhou, Oct. 2018, pp. 367-371, doi: 10.1109/ICCAIS.2018.8570323.

[22] R. Banerjee and A. Pal, 'Stabilization of Inverted Pendulum on Cart Based on LQG Optimal Control', in 2018 International Conference on Circuits and Systems in Digital Enterprise Technology (ICCSDET), Kottayam, India, Dec. 2018, pp. 1-4, doi: 10.1109/ICCSDET.2018.8821243.

[23] R. Banerjee, N. Dey, U. Mondal, and B. Hazra, 'Stabilization of Double Link Inverted Pendulum Using LQR', in 2018 International Conference on Current Trends towards Converging Technologies (ICCTCT), Coimbatore, Mar. 2018, pp. 1-6, doi: 10.1109/ICCTCT.2018.8550915.

[24] A. Besancon-Voda, G. Filardi, D. Rey, and A. Franco, 'LQG optimal control strategies for an electro pneumatic actuator', in 2001 European Control Conference (ECC), Porto, Sep. 2001, pp. 2670-2675, doi: 10.23919/ECC.2001.7076333. 
[25] Q. Jin, S. Ren, and Ling Quan, 'LQG optimum controller design and simulation base on inter model control theory', in 2009 IEEE International Conference on Intelligent Computing and Intelligent Systems, Shanghai, China, Nov. 2009, pp. 62-65, doi: 10.1109/ICICISYS.2009.5358234.

[26] B. Kurucso, A. Peschka, P. Stumpf, I. Nagy, and I. Vajk, 'State space control of quadratic boost converter using LQR and LQG approaches', in 2015 Intl Aegean Conference on Electrical Machines \& Power Electronics (ACEMP), 2015 Intl Conference on Optimization of Electrical \& Electronic Equipment (OPTIM) \& 2015 Intl Symposium on Advanced Electromechanical Motion Systems (ELECTROMOTION), Side, Sep. 2015, pp. 642-648, doi: 10.1109/OPTIM.2015.7427003.

[27] R. Soni and Sathans, 'Optimal control of a ball and beam system through LQR and LQG', in 2018 2nd International Conference on Inventive Systems and Control (ICISC), Coimbatore, Jan. 2018, pp. 179-184, doi: 10.1109/ICISC.2018.8399060.

[28] J. Vlk and P. Chudy, 'General aviation digital autopilot design based on LQR/LQG control strategy', in 2017 IEEE/AIAA 36th Digital Avionics Systems Conference (DASC), St. Petersburg, FL, Sep. 2017, pp. 1-9, doi: 10.1109/DASC.2017.8102058.

[29] M. Ho, Y. Tu, and H. Lin, 'Controlling a ball and wheel system using full-state-feedback linearization [Focus on Education]', Control Syst. IEEE, vol. 29, pp. 93-101, Nov. 2009, doi: 10.1109/MCS.2009.934085.

[30] M. Moarref, M. Saadat, and G. Vossoughi, 'Mechatronic design and position control of a novel ball and plate system', in 2008 16th Mediterranean Conference on Control and Automation, Ajaccio, France, Jun. 2008, pp. 1071-1076, doi: 10.1109/MED.2008.4602212.

[31] S. A. Moezi, E. Zakeri, Y. Bazargan-Lari, and M. Khalghollah, 'Fuzzy Logic Control of a Ball on Sphere System', Adv. Fuzzy Syst., vol. 2014, pp. 1-6, 2014, doi: 10.1155/2014/291430.

[32] S.-Y. Liu, Y. Rizal, and M.-T. Ho, 'Stabilization of a Ball and Sphere System Using Feedback Linearization and Sliding Mode Control', in 2011 8th Asian Control Conference (ASCC), May 2011, p. 6.

[33] E. Zakeri, A. Ghahramani, and S. Moezi, 'Adaptive Feedback Linearization Control of a Ball on Sphere System', in International Conference on Mechanical Engineering and Advanced Technology, ICMEAT 2012, Isfahan, Iran, Oct. 2012, pp. $1-5$.

[34] A. Tewari, Modern control design with MATLAB and SIMULINK. New York: John Wiley, 2002.

[35] G. Welch and G. Bishop, 'An Introduction to the Kalman Filter'. 2006.

[36] R. Eide, P. M. Egelid, A. Stamsø, and H. R. Karimi, 'LQG Control Design for Balancing an Inverted Pendulum Mobile Robot', Intell. Control Autom., vol. 02, no. 02, pp. 160-166, 2011, doi: 10.4236/ica.2011.22019.

[37] R. S. Burns, Advanced control engineering. Oxford, Boston: Butterworth-Heinemann, 2001.

[38] U. Mohammed, S. U. Hussein, M. Usman, and S. Thomas, 'Design of an Optimal Linear Quadratic Regulator (LQR) Controller for the Ball-On-Sphere System', International Journal of Engineering and Manufacturing(IJEM), vol. 10, no. 3, pp. 56-70, Jun. 2020, doi: 10.5815/ijem.2020.03.05.

\section{Author's Profile}

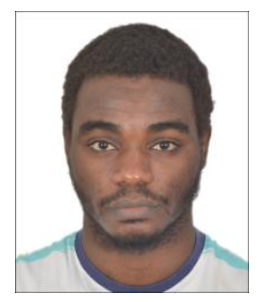

Usman Mohammed is a student in the Department of Electrical and Electronics Engineering, Nile University of Nigeria, Abuja, Nigeria. He completed his Bachelor's degree in Physics in 2016 at Fatih University, Istanbul, Turkey, and a Postgraduate Diploma (PGD) in Electrical and Electronics Engineering in 2019 at Nile University of Nigeria, Abuja, Nigeria. Currently, he is pursuing a Master's degree in Electrical and Electronics Engineering at Nile University of Nigeria, Abuja, Nigeria.

How to cite this paper: Usman Mohammed, Tologon Karataev, Omotayo O. Oshiga, Suleiman U. Hussein, Sadiq Thomas, " Comparison of Linear Quadratic - Regulator and Gaussian - Controllers' Performance, LQR and LQG: Ball-on-Sphere System as a Case Study ", International Journal of Engineering and Manufacturing (IJEM), Vol.11, No.3, pp. 45-67, 2021. DOI: 10.5815/ijem.2021.03.05 